University of Louisville ThinkIR: The University of Louisville's Institutional Repository

Electronic Theses and Dissertations

$5-2019$

\title{
An evaluation of student perceptions of learning environments across fully on-line versus blended course delivery formats.
}

Pamela Bates Larkin

University of Louisville

Follow this and additional works at: https://ir.library.louisville.edu/etd

Part of the Curriculum and Instruction Commons, and the Online and Distance Education Commons

\section{Recommended Citation}

Larkin, Pamela Bates, "An evaluation of student perceptions of learning environments across fully on-line versus blended course delivery formats." (2019). Electronic Theses and Dissertations. Paper 3200.

https://doi.org/10.18297/etd/3200

This Doctoral Dissertation is brought to you for free and open access by ThinkIR: The University of Louisville's Institutional Repository. It has been accepted for inclusion in Electronic Theses and Dissertations by an authorized administrator of ThinkIR: The University of Louisville's Institutional Repository. This title appears here courtesy of the author, who has retained all other copyrights. For more information, please contact thinkir@louisville.edu. 


\title{
AN EVALUATION OF STUDENT PERCEPTIONS OF LEARNING \\ ENVIRONMENTS ACROSS FULLY ON-LINE VERSUS BLENDED COURSE \\ DELIVERY FORMATS
}

\author{
By \\ Pamela Bates Larkin \\ BS, Berea College, 1986 \\ MAT, University of Louisville, 1992
}

\begin{abstract}
A Dissertation
Submitted to the Faculty of the College of Education and Human Development of the University of Louisville in Partial Fulfillment of the Requirements for the Degree of
\end{abstract}

Doctor of Philosophy in Curriculum \& Instruction

Early Childhood and Elementary Education, Middle and Secondary Education, and Special Education

University of Louisville

Louisville, Kentucky

May 2019 



\section{AN EVALUATION OF STUDENT PERCEPTIONS OF LEARNING ENVIRONMENTS ACROSS FULLY ON-LINE VERSUS BLENDED COURSE DELIVERY FORMATS \\ By \\ Pamela Bates Larkin \\ BS, Berea College, 1986 \\ MAT, University of Louisville, 1992}
A Dissertation Approved On
April 10, 2019

By the Dissertation Committee

Dr. Timothy J. Landrum, Chair

Dr. Richard Balkin

Dr. James S. Chisholm

Dr. Jessica Hardy 


\section{DEDICATION}

I dedicate this dissertation to four influential people in my life.

First, my grandmother, Hazel Collins. She often asked me what I did for a living.

I would tell her "teach college" to which she would reply, "Have you gone to school long enough to teach college?" Yes, Mamma, I have.

Second, my mother, Eulah Mae Bates. She was the driving force behind the evolution of this independent, fierce woman she insisted I become.

Third, my father, Noel Bates. I wish you were here to share this with me. I hope you are proud.

Lastly, my ever supportive and encouraging husband, Steve. You are a truly loving man who makes me feel I can accomplish anything I set my mind to it.

To all my family and friends, I cannot thank you enough for encouraging me to continue this journey. Thank you for taking this adventure with me.

"For I know the plans I have for you," declares the Lord, "plans to prosper you and not to harm you, plans to give you hope and a future." Jeremiah 29:11 


\section{ACKNOWLEDGEMENTS}

As I have traveled through a life-long education, I have been fortunate to have three professors that have been my mentors and have given me aspirations of reaching the level of professionalism and caring they offered.

Mr. Boes was my business administration instructor at Berea College. He was an encourager and shared his love of teaching willingly. We forged a friendship that lasted until his passing in 2014.

As my advisor, instructor, and doctoral program chair, Dr. Randall Wells guided me through my coursework toward this degree. He was a supporter who taught me through example much of the teaching methods I use today. His passion for teaching and learning as well as students spurred a love of teaching in me.

Dr. Timothy Landrum, my dissertation committee chair and mentor, has been instrumental in my completion of this dissertation. He has spent many hours working through the process and my endless questions. He is appreciated more than he can know.

Dr. Brittany Inge: Thank you for the emailing the survey to the participants. I appreciate your willingness to help a colleague.

My dissertation committee - Dr. Richard Balkin, Dr. James Chisholm, and Dr. Jessica Hardy: I appreciate you taking on a doctoral candidate that has been at the University of Louisville longer than most faculty in the College of Education. You had no prior connection to me but were willing to share your time and thoughts to help me complete this endeavor. 


\begin{abstract}
AN EVALUATION OF STUDENT PERCEPTIONS OF LEARNING

ENVIRONMENTS ACROSS FULLY ON-LINE VERSUS BLENDED COURSE

DELIVERY FORMATS

Pamela Bates Larkin
\end{abstract}

April 10, 2019

The primary focus of this evaluation study was to describe students' perceptions of their course experiences within two distinct groups of students who participated in either a fully online or a hybrid/blended version of an introductory course. The groups differed in course format (hybrid versus online group) and measures used included primarily the seven scale scores on the Distance Education Learning Environments Survey (DELES) (Walker \& Fraser, 2005). Additionally students were asked to respond to one open-ended question designed to assess perceptions of the course delivery format specifically. Although findings must be interpreted with great caution, due primarily to low response rates, a sample limited to one community college, and a focus on perceptions alone rather than broader outcomes, the evaluation study leads to a number of preliminary conclusions. First, it appears that one key outcome from the survey is that students desire that instructors provide constant and prompt feedback to students whether it be negative or positive communication. Second, being able to apply the course content to workplace or life situations was seen as valuable to the students in the online section more so than those in the hybrid section. Third, while there was some negativity from the 
students enrolled in the online section, overall the comments in the open-ended questions portrayed the instructor in a positive light. Suggestions for further research on this topic include accessing broader and more diverse and representative samples of student participants, working to ensure higher response rates, and gaining measures of actual course impacts on learning or other performance outcomes, rather than relying on perceptions alone. 


\section{TABLE OF CONTENTS}

SECTION

PAGE

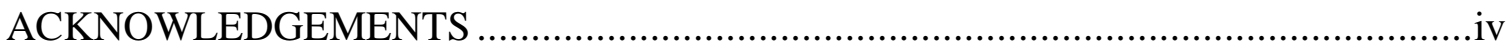

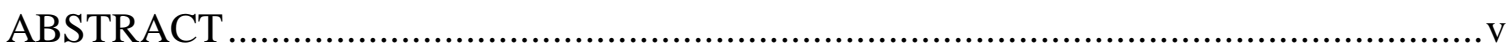

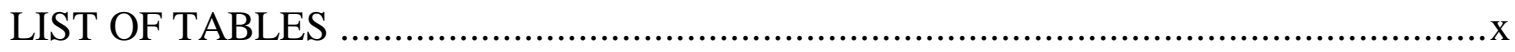

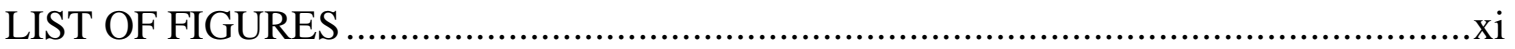

CHAPTER 1: INTRODUCTION ..................................................................

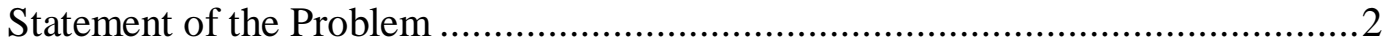

Purpose ..........................................................................................

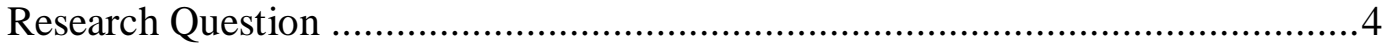

Definition of Terms ...........................................................................

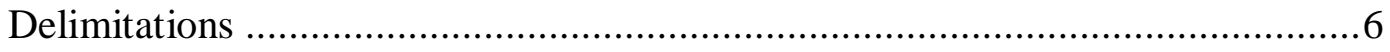

CHAPTER 2: LITERATURE REVIEW ....................................................

Measures Used in Previous Research ....................................................... 9

Comparison of Hybrid vs. Online …........................................................ 11

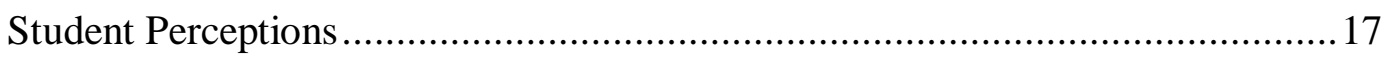

Survey Response Rates ..................................................................... 18

CHAPTER 3: METHODS ................................................................................... 22

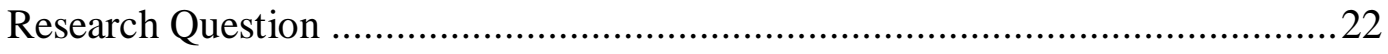

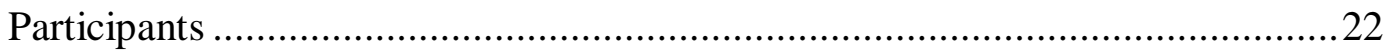

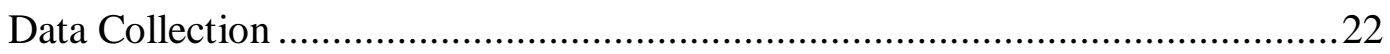




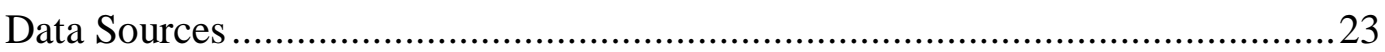

The Distance Education Learning Environments Survey (DELES) ....................24

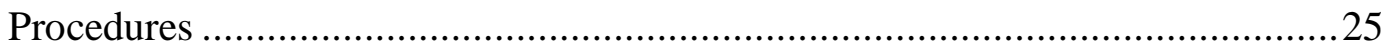

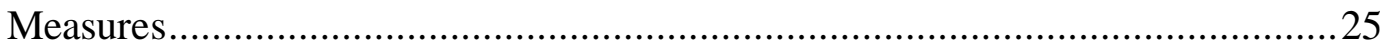

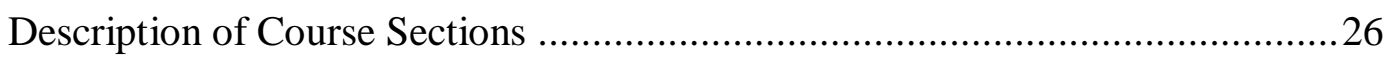

Key Distinctions between Hybrid and Online Sections ....................................22

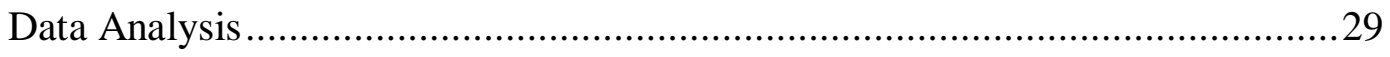

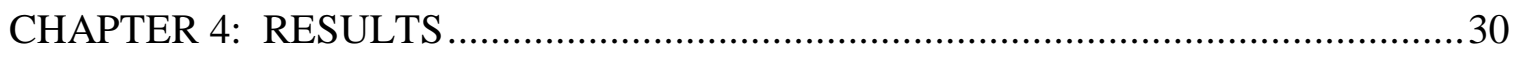

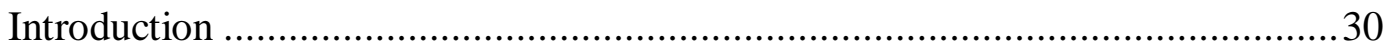

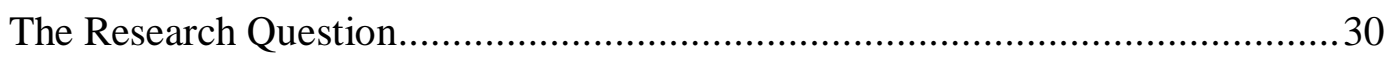

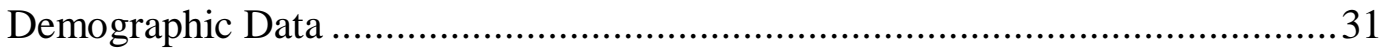

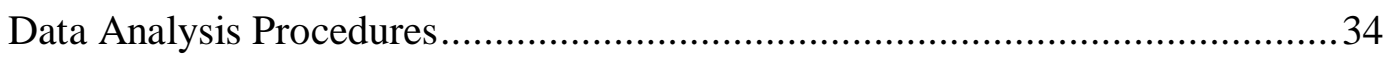

Box and Whisker Plots of DELES Scales .......................................................4

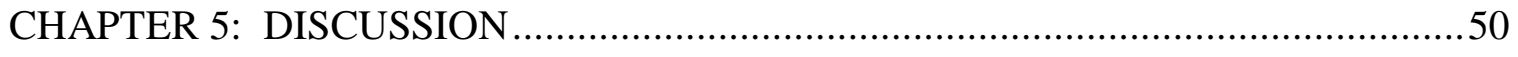

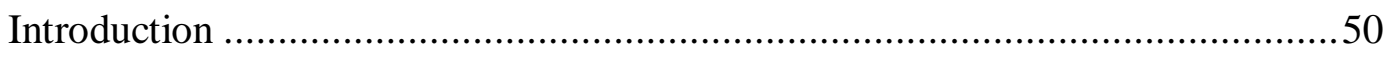

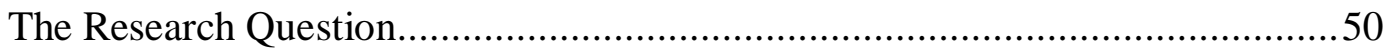

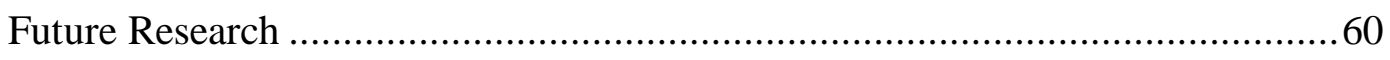

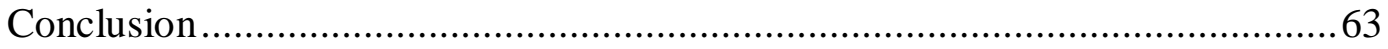

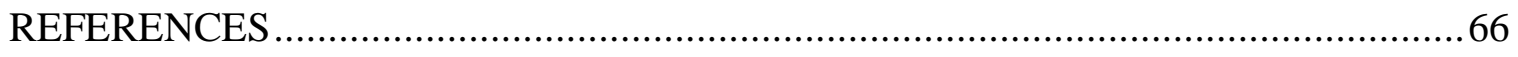

APPENDICES

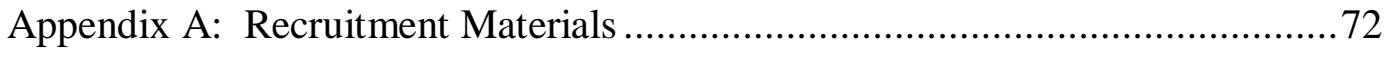

Appendix B: Follow-up Email.................................................................... 74

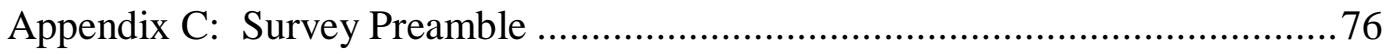


Appendix D: Demographic Form ..................................................... 79

Appendix E: Distance Education Learning Environments Survey (DELES) ......81

Appendix F: Open-Ended Question for Participants Who Completed DELES

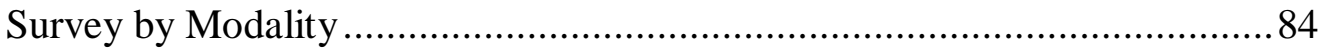

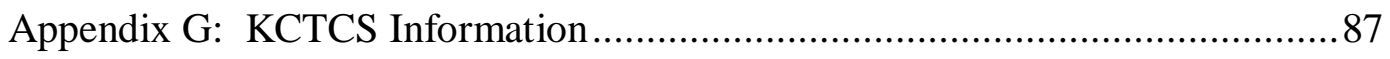

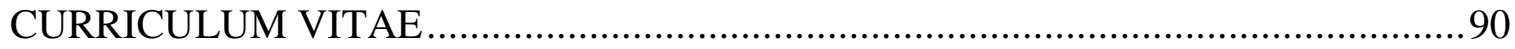




\section{LIST OF TABLES}

TABLE

PAGE

1. Key Distinctions Between Hybrid And Online Sections ...................................28

2. Number of Participants Who Completed DELES Survey ....................................31

3. Age of Participants Who Completed DELES Survey by Modality ...........................32

4. Demographic Data for Participants Who Completed DELES

Survey by Modality.

5. Experience or Prior Training Data for Participants Who Completed DELES Survey

by Modality .33

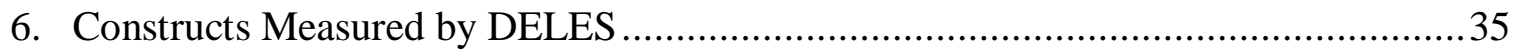

7. DELES Scale 1: Instructor Support .................................................... 36

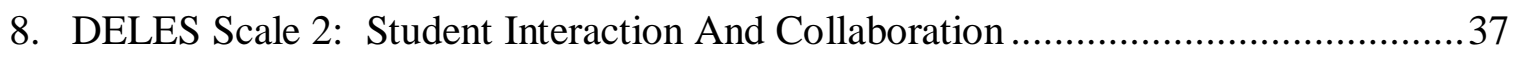

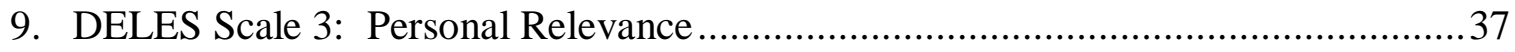

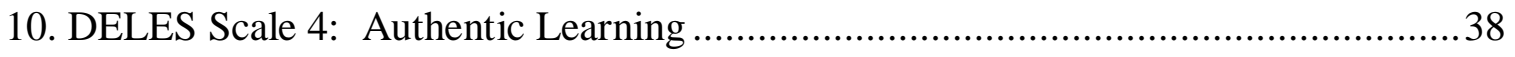

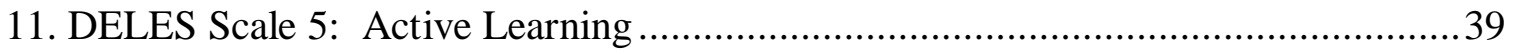

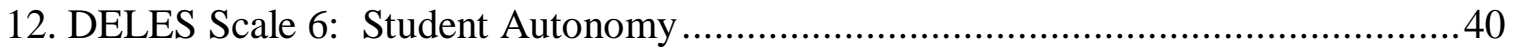

13. DELES Scale 7: Distance Education ....................................................... 41 


\section{LIST OF FIGURES}

FIGURE

PAGE

1. DELES Scale 1: Instructor Support Box and Whisker Plot ...............................42

2. DELES Scale 2: Student Interaction And Collaboration Box and Whisker Plot .......43

3. DELES Scale 3: Personal Relevance Box and Whisker Plot................................ 44

4. DELES Scale 4: Authentic Learning Box and Whisker Plot ..............................45

5. DELES Scale 5: Active Learning Box and Whisker Plot .................................46

6. DELES Scale 6: Student Autonomy Box and Whisker Plot................................46

7. DELES Scale 7: Distance Education Box and Whisker Plot .................................47 


\section{CHAPTER 1}

\section{INTRODUCTION}

Educators at all levels are continually encouraged by administration to embrace technology in the classroom, whether it be as an instructional aid to enhance students' learning in the classroom or as a means to deliver instruction either fully or partially online (Allen \& Seaman, 2009). One problem confronting K-12 education is the dramatic shift in the levels of comfort and facility with technology that children bring to school. In short, it may often be the case that because some students have used technology (i.e., smart phones, tablets, apps) virtually from birth, they may have a higher level of comfort and facility with technology than their teachers (Purcell et al., 2013). This phenomenon plays out at the college level as well, and college and university faculty must continually upgrade their own skills and use of technology by seeking training and ongoing professional development in instructional technology, including the use of web-based or

online course delivery. Despite the rapid expansion of technology and the dominance of technology in everyday life, concerns about a "digital divide" remain, and some percentage of children come to school with limited exposure to and experience with basic technology. "Even as Internet use increased dramatically overall, a rural/urban gap remained in 2015, with 69 percent of rural residents reporting using the Internet, versus 75 percent of urban residents" (Carlson \& Goss, 2016). For students entering college, competence with basic technology is often an explicit expectation: even for courses taught completely in person, or face-to-face, students access materials and conduct 
library research online, submit most assignments electronically, and communicate with their instructors and classmates through email or other web-based forums (chatrooms, discussion boards). However, for a significant population of students, including largely though not exclusively nontraditional students (e.g., older students attending college for the first time, career switchers), limited experience with technology or anxiety about technology may present particular problems.

\section{Statement of the Problem}

Given the likelihood that (a) college course delivery is increasingly technologyreliant, but that (b) students pursuing college-level work-- especially non-traditional students-- will vary considerably in their experience and comfort level with technology, many questions remain for college instructors and administrators about how best to deliver college coursework in ways that meet the needs of students. Importantly, this involves several related concepts. First, it is important to know whether and how different modes of coursework delivery impact students' acquisition of knowledge and skills. Depending on the nature and purpose of the course, students may be expected to master a set of facts and information-- a body of knowledge. Conversely, or perhaps in addition, they may be asked to acquire a specific skill set and demonstrate mastery in their ability to perform or execute certain tasks.

A second and highly related concept involves students' perceptions of their coursework experience. Clinefelter and Aslanian (2016) stated, "successful past experiences most likely contribute positively to bringing these students back to the online modality as they seek to further or complete their education" (p. 13). This suggests that if students perceive their coursework to be a positive experience, they will be both more 
likely to remain engaged with and active in a given course, but also potentially more likely to persist in pursuing a line of study or degree program. As Dobbs et al. (2009) noted, "those students in the sample who had online experience tended to view that experience in a positive light and reported that they would take more online courses in the future" (p. 23).

With regard to technology in particular, it might be hypothesized that students with different levels of experience and comfort in using technology will differ in both their success in individual courses and their persistence in degree programs that rely heavily on technology-driven course delivery. Not surprisingly, given the newness and rapidly changing landscape of instructional technology, research on the intersection of these topics is extremely limited. Indeed, the internet as we know it today is less than two decades old, and the technologies currently in use in instructional contexts are constantly changing and evolving, often in dramatic ways.

The initial research on technology-driven course delivery included comparisons that focused on differences between traditional (face-to-face) course delivery and other means of course delivery: traditional versus online coursework (Botsch \& Botsch, 2001), or traditional versus hybrid coursework (Black, 2002). Such comparative studies addressed instructors' and administrators' need to learn about alternatives to traditional course delivery, as technological advances and an increasingly competitive higher education marketplace make effective, efficient, and student-friendly course delivery a high priority. Rather than simply moving traditional classes to an online format, however, there may be advantages to students in an intermediate step, namely the development and delivery of hybrid courses that combine elements of online and face-to- 
face instruction. However, virtually no studies have directly evaluated differences between online and hybrid delivery options. Thus, the present study was designed as an evaluation to address this need by describing student perceptions of the learning environment in college courses delivered either fully online or via a hybrid course delivery model including a brief assessment of students' perceptions of the impact of such courses on their learning outcomes.

\section{Purpose}

The purpose of this evaluation study is to assess the perceptions of community college students taking different versions of an introductory computer literacy course in terms of their experiences in learning computer literacy content through one of two course delivery methods. The course content is identical in all sections of the course, and the course instructor is the same; the only difference is in course delivery method. Approximately half of the students surveyed had taken a fully-online version of the course; the other half had taken a hybrid (blended) version of the course, in which half of class sessions involved live, face-to-face instruction in the classroom, and the other half involved online instruction.

\section{Research Question}

The question driving this evaluation study was:

What is the nature of students' perceptions of their learning experiences in a course delivered though a hybrid (blended) versus fully online instructional format?

Student perceptions of their course experience was measured by the Distance Education Learning Environments Survey (DELES) (Walker \& Fraser, 2004). In addition 
to collecting data on perceptions as captured by the DELES, I also collected information in a brief demographic survey regarding basic demographics (age, gender, ethnicity) as well as students' experience and prior learning regarding technology (e.g., high school and previous college courses with a technology component, prior work experience or training in technology or technology-related content). Through qualitative analyses of student responses to one open-ended question, I sought to triangulate data gathered through the DELES in order to better understand students' perceptions, and determine whether any relationships might be evident among students' perceptions of their course experience and their prior experiences, as well as basic demographics. For example, there is often an assumption in the work place and educational environments that older students may be less technologically savvy or comfortable with technology than younger students, and I attempted to explore this topic in analyses of the data collected as part of this study.

\section{Definition of Terms}

Hybrid course delivery - refers to a course in which content is offered primarily within an online platform, but which also includes at least periodic face-to-face class meetings with the instructor an classmates.

Online course delivery - refers to a course in which content is delivered entirely through an online platform; students interact with the instructor and classmates via online tools (chats, discussion boards, email), but do not interact face-to-face with an instructor or classmates during the course.

Traditional course delivery - involves regularly scheduled in-person class meetings which include instruction and interactions with instructors and classmates; 
content may be supported by online tools (e.g., BlackBoard), but instruction is delivered via in-person interactions.

\section{Delimitations}

Given the dearth of research on the differences between online and hybrid course delivery modes, this evaluation study represents a small first step in assessing student perceptions across these two delivery methods. In order to help control for potential

differences in courses, I used a relatively small sample of students in two parallel sections of the same course, each delivered through a different course delivery mode (one hybrid, one fully online). 


\section{CHAPTER 2}

\section{LITERATURE REVIEW}

In this chapter, I provide an overview of the literature that leads to the questions underlying this evaluation study. Following a brief introduction and overview of key terminology and concepts, including measures used in previous research, I review literature on (a) age and gender differences in technology use and preferences, and (b) technology use in hybrid and online classrooms. Because the response rate for the present study was ultimately lower than anticipated, I also include a brief overview here of literature on response rates.

Much of the early literature regarding online learning was centered on a comparison and contrast between traditional (i.e., face-to-face, or in-person) course delivery and online modes of delivery (e.g., Botsch \& Botsch, 2001). More recently, a hybrid mode of delivery is used increasingly in which face-to-face and online teaching modes are blended. For the purposes of this dissertation, Traditional learning is defined as synchronous, face-to-face $(\mathrm{F} 2 \mathrm{~F})$, in person classes with an instructor leading instruction, which may include presenting lectures, demonstrating, or facilitating interaction or discussion in real time. Online learning is defined as asynchronous webbased delivery of coursework, in which students work independently on their own schedule via computer and internet technology. Hybrid learning is a mixture of the two delivery methods with some time spent in the traditional classroom setting with 
interaction between the instructor and students, and the remaining coursework completed outside the classroom independently by students.

With the advent of the internet and its usage becoming more common in the early 1990's, online education became more readily available. Students were no longer bound to the classroom in the traditional meaning. The classroom became any location that a student was in while logged on to the course portal or website. The first courses offered online consisted largely of synchronous delivery of coursework from a distance; students were required to log into the class website at the same time for a live discussion that could involve all students who were logged in. Prior to the evolution of web-based video technologies that allowed for video and audio interactions, the "interaction" that occurred involved students typing in responses which all class members could see and engaging in online discussions. Instructors could participate as well, and could see if the student "came to class" and the extent to which they "participated" based on the number and nature of responses he/she posted at that prescribed time.

As the concept evolved, class time became less important. Materials were posted on the class website, and the student could access them whenever needed. The only time constraints were due dates for assignments or tests. Many courses now are not only asynchronous, but are also self-paced; that is, all course materials are posted at the beginning of the semester allowing the student to complete the entire course at his or her own pace. As online learning first became more widely available, many students saw this as a highly appealing option, based largely on convenience. At the same time, there was little research to guide practice in the delivery of online learning, and not surprisingly many students embraced this style of learning despite, or perhaps without really 
considering, a number of potential drawbacks. Not all students are online learners. They do not possess the computer savvy necessary to navigate the course and complete the work.

According to Allen and Seaman (2006), the number of students enrolled in at least one online course during the Fall 2005 semester was nearly 3.2 million. The larger enrollments were in the private sector. For-profit institutions capitalized on this method of delivery. Students who were struggling to work and attend traditional classes were very accepting of the alternate way to complete a post-secondary education. Public institutions were slower to respond but have seen major increases as well. Students were happy to remain in their dorm rooms taking a class online as opposed to attending in person. By the Fall 2009 semester, enrollment in online courses had grown to over 5.6 million students, and by 2014, the number of students enrolled in distance education was 5.8 million (Allen \& Seaman, 2015).

\section{Measures Used in Previous Research}

Student grades were often the focus of evaluation of early online vs. traditional classroom learning. In 2001, Miller, Cohen, and Beffa-Negrini developed a multiplechoice instrument designed to ascertain whether the students in online and traditional sections gained basic nutrition knowledge of the course. The instrument was given as a pretest and posttest. The students in the two sections showed the same knowledge gains between pretest and posttest, but the online students had slightly higher overall course grades. The older online students performed better in both sections than younger students in either and older students in the traditional setting. "The results found in this study 
indicate that students received benefits from both lecture and online instruction" (Miller et al., 2001, p. 9).

Hybrid learning combines the traditional and online learning environments utilizing both synchronous and asynchronous delivery. According to Black (2002), "it is up to the teacher to determine what aspects of the course are best suited to presentation via the various delivery modes" (p. 2). In theory, hybrid courses are the best education has to offer. Students are offered a time for interaction with the instructor and classmates as well as motivation provided by the instructor. However, the student is further benefited by having the time to complete coursework independently when his/her schedule allows within the guidelines of the course due dates. Jackson and Helms (2008) stated, "the hybrid format is stuck in the middle of two disparate pedagogies or extremes and appears to suffer from both the strengths and the weaknesses at either extreme" (p. $11)$.

In 2011, Tsai et al. conducted a study with 112 vocational students in a database management course. Students were placed into three experimental groups, each having blended learning with 5 or 10 online classes and the remainder of the classes in the traditional classroom setting. The computing skills of the students were pre-tested and found be similar. All classroom lectures were recorded and provided to the students on the course website. The intervention used was to provide the students in two of the groups with training on self-regulated learning. The students were taught how to evaluate their learning using the four processes of self-regulated learning described by Zimmerman et al. (1996). 
The first research question was to determine the effect of online class frequency on the computing skills of students. The results showed that "a blended course with 5 online classes may result in better learning effects than that with 10 online classes" (p. 265). Thus, the higher frequency of the online class may not improve the computing skills.

Students were also asked how they felt about the blended learning class. "Based on the overall analysis and student's opinions and preference presented in this subsection, it is found that a course with more (10) online classes may not result in better thoughts than one with fewer (5) online classes" (Tsai et al., p. 267). Tsai et al. suggested that further study should be conducted on the efficacy of online and traditional instruction: "it is further suggested that teachers should consider their national education policy and individual teaching context, and design an appropriate arrange of blended course that fits their students' need and characteristics, and contributes to students' quality learning" (p. 269). The authors also recommended exploring innovative teaching methods and technologies to fully utilize the benefits of hybrid learning for the students.

\section{Comparison of Hybrid vs. Online}

The lack of research on the efficacy of hybrid vs. online classes is the driving force behind this evaluation study. Educators are being encouraged to offer more hybrid classes to lessen the use of the college's physical resources, and to make courses and degree programs more appealing to students. Hybrid classes use less of the brick and mortar structure of colleges and universities, and more technology while maintaining interaction between the instructor and students and among the students. However, there is little research to indicate whether this delivery method is in fact increasing students' 
depth of knowledge and success as defined by specific learning outcomes. The small body of research to date has focused on a few key variables.

Age. Much of the early research in online learning focused on demographics. While the main focus of a study by Miller, Cohen, and Beffa-Negrini (2001) was material knowledge, the researchers found that older students had higher grades than their younger classmates in their comparison between online and face-to-face instruction.

More recent research by Driscoll, Jicha, Hunt, Tichavsky, and Thompson (2012) indicated that students enrolled in online courses "tended to be older, to have taken more online courses, and to work more hours during the week" (p. 320).

A trend toward the majority of students enrolling in online courses being non-traditional appears to have continued. In their 2015 study, Ganesh, Paswan, and Sun found, "The online students were older, lived further from the university town, and had greater experience with online classes than the face-to-face students."

According to Clinefelter and Aslanian (2016), "The typical online student has been changing over the past five years. Online college students are getting younger as the average age has dropped to 29 for undergraduate online students and to 33 for graduate online students. They are also more likely to be single and have fewer children" (p. 18). This seems to indicate enrollment in online learning could be for reasons other than life circumstances.

Gender. Botsch and Botsch (2001) found that more women enrolled in both the traditional and web-based courses they studied. Their results also showed that different groups of students tended to enroll in web classes than in traditional classes; web-based classes were reaching an older audience. 
The National Student Clearinghouse Research Center (2018) reported enrollments in all sectors of Title IV, Degree granting institutions to be 7,573,875 males (42.4\%) and $10,265,455$ females $(57.6 \%)$. The findings were consistent with the gender demographics reported in Spring 2017 and Spring 2016 (p. 11).

In comparing the effectiveness of hybrid vs. traditional classes, Adams, Randall, and Traustadóttir (2014) reported "no significant differences in class performance within each section between males and females or between majors" (p. 4). Studying perceptions may lend to a distinction between the age and gender of online and hybrid learners that class performance or course outcomes may not identify.

Student outcomes/learning. When researchers began to further investigate hybrid vs. online learning, student grades, and other pre- and post-test assessments were generally the basis for such evaluations. For example, in a simple comparison of the two formats, Adams, Randall, and Traustadóttir (2014) conducted a study using two sections of an introductory microbiology course. One section was taught in the traditional setting while the other was taught as a hybrid. The same instructor taught both sections. Final grades and a midterm survey revealed, "students in the hybrid section were less successful than those in the traditional section" (p. 7)

Cosgrove and Olitsky (2015) studied three modes of course delivery: hybrid (these authors used the term blended), web-enhanced, and traditional. They further distinguished the difference between hybrid and web-enhanced as having the same course materials but having less online work. They found no significant difference in student scores between the hybrid and web-enhanced courses. They concluded "As a result, there is no evidence that one mode of study is better than others in helping students 
acquire the content knowledge" (p. 574). However, students in the traditional classes retained a higher level of content than students in the hybrid or web-enhanced classes.

The results of the study of perceptions of the online and hybrid students in the differing learning environments may allow the instructor to modify the course structure and materials in a way that allows for more knowledge retention and increase student outcomes.

Student perceptions. Black (2002) conducted a survey with students enrolled in online (termed Internet in this study), traditional, and hybrid course delivery to assess student satisfaction. The perceived ease of use in the delivery mode and the level of course satisfaction were positively correlated. "Course delivery mode, usefulness, ease of use and flexibility were significantly related to course satisfaction" (p. 6). This study indicated that students in the hybrid classes perceived that having the duality of classroom and technology-based learning was superior to either online or traditional delivery modes. However, the author felt that these findings were not causal but were an indicator that more research should be done. Black went on to say that keeping the course objectives at the forefront of pedagogy and delivery would determine which mode of delivery would be best to use, suggesting that educators will need to revise their teaching styles and methods to make way for new approaches to meeting the needs of the students. He concluded "there is a need for specifically focused research to develop an appropriate pedagogy for both hybrid and web-based modes of delivery" (p. 8).

Lim, Morris, and Kupritz (2007) also used a survey “to obtain the learners' perceived degree of learning, learning application, and instructional quality of the course" (p. 29). The questionnaire consisted of Likert-style questions and open-ended questions 
and was administered at the beginning and ending of the semester. The findings were consistent with other studies of online vs. hybrid course in that the mode of delivery did not affect learning. Yet, the study did find that students in the online courses reported a larger workload than the students in the hybrid classes. Lim et al. concluded "the findings suggest that an important consideration in designing online and blended instruction is to include instructional activities and collaboration opportunities that enhance the learners' emotional engagement with peers and instructors." This may lend to the students feeling a sense of "presence" in the class. The authors went on to say that the instructions given in the blended learning situation were thought to be clearer and more learner-centered than in the online learning situation. Lastly, the practical and personal application of material presented in the courses regardless of delivery method were valued by the students.

In 2009, Collopy and Arnold studied online vs. hybrid (termed blended) learning environments in a teacher education program to determine "the impact on student learning", "importance of student comfort", and "possibilities for teamwork in a virtual experience" (p. 86). The students in the blended courses reported higher levels of learning than the students in the online courses. The online learners reported feeling less comfortable with the content and in using it than the blended learners. "In this study, it is possible that the face-to-face interaction with the instructor and other teacher candidates supported confidence and comprehension of the material" (p. 97). The authors felt that there was more time in blended courses for teambuilding and being face-to-face allowed the students to develop their teamwork skills. Then the students were allowed to work 
independently and have time to think and process the material presented in the traditional environment.

While Cosgrove and Olitsky (2015) found no significant difference in the delivery mode of the classes they studied, they did find that students in traditional classes retained the course material longer than in the more technology-based courses. They suggest that future research should be done on the study habits of the students in each type of course. Further, they questioned whether the interaction between the instructor and students and among students played a role in the material retention.

Finally, Martin, Kreiger, and Apicerno (2015) use demographic information as a way to collect data on past experience with online courses and thoughts on future enrollments. The authors found no significant differences between the traditional and hybrid classroom students in previous experience or in thinking they may enroll in online classes in the future. Importantly, authors of all of the studies posed future research questions regarding larger, more varied populations, different course topics, and more differentiation in the pedagogies for all delivery modes.

This evaluation study will address some of the topics suggested for future research in the literature reviewed here by synthesizing the perceptions of the students enrolled in the varying learning environments. The importance of instructor support and active learning will be examined. Using the DELES, I will also attempt to discern whether students find the coursework personally relevant or authentic. While the original plan for this study included potential analyses for differences across gender or age ranges, in students' perceptions of the two different course formats, limited sample size and 
diversity, and a lower than expected response rate, precluded any statistical analyses involving these demographics.

\section{Student Perceptions}

Research suggests that learning environments matter a great deal in terms of the effort students put into courses, the enjoyment they find in participating in courses, and, presumably related to these elements, the amount of learning that takes place (e.g., Walker \& Fraser, 2005). Beginning in the 1960s, researchers began to establish that students' perceptions of their learning environments are in fact associated with specific student outcomes (Anderson \& Walberg, 1968; Walberg, 1979). A key element of this body of research was the development and validation of a number of assessments that can be used to assess learning environments. Important early developments in this regard included the Learning Environment Inventory (LEI), developed by Walberg (1968), and Classroom Environments Scale, developed by Moos (1974); both were used extensively in early classroom environment research. This body of early research established that students' perceptions in fact matter a great deal, and scholars have consistently concluded that students' perceptions of their learning environments are associated with student outcomes. Walker and Fraser (2005), for example, concluded, "Learning environments research has consistently demonstrated that, across nations, languages, cultures, subject matter, and educational levels, there are consistent and appreciable associations between classroom environment perceptions and student outcomes" (p. 294).

In recent decades, the rapid expansion of technology has resulted in a dramatic shift in the range and types of educational environments students experience; distance education (DE) course delivery has become common across higher education worldwide. 
However, despite the volume of research documenting the importance of students' perceptions of their learning environments in predicting outcomes, and a growing body of research on distance education course delivery generally, relatively little research has explored students' perceptions of their DE experiences from a learning environments perspective. Scholars have acknowledged that the rapid development of technology and the evolution of varied and multifaceted methods of technology-driven course delivery (e.g., fully online, synchronous versus asynchronous course delivery, hybrid or blended course delivery, etc.) have contributed to the failure of research to keep pace with the realities of DE course delivery.

Blended and online learning environments vary in ways that affect student perceptions. By studying student perceptions of these different course delivery methods, future instructors could structure courses to create more positive learning experience and in turn, potentially increase student outcomes, retention, and persistence.

\section{Survey Response Rates}

Much has been written on survey response rates since 1838 when Galton introduced the first questionnaire in behavioral science. Also being credited with founding behavioral and educational statistics, his questionnaires were invaluable to analytical frameworks (Clauser, 2007). For purposes of this evaluation study, I briefly

review specific literature on more recent research utilizing electronic data gathering, especially given that access to the internet, and the expansion of internet use has occurred.

Moving to an electronic survey system can provide advantages related to cost and timeliness. "Using web-based evaluation questionnaires can bypass many of the 
bottlenecks in the evaluation system (e.g. data entry and administration) and move to a more 'just in time' evaluation model" (Watts et al., 2002. p. 327). Online surveys also allow instructors to use class time for instruction instead of survey completion (Dommeyer et al., 2004).

A good deal of the research into response rates in the early 2000s showed that web-based surveys provided lower response rates than paper surveys. In 2000, Cook, Heath, and Thompson completed a meta-analysis of electronic survey response rates. The findings indicated that electronic questionnaires did not increase the number of responses. This was further researched, and the general finding was supported, by Nulty (2008).

Response rates have also been the subject of research as online surveys have become more common. "Survey researchers classify the reasons for nonresponse into three basic categories: noncontact, meaning that interviewers or screeners were unable to communicate with a targeted respondent; refusals, in which contact is established but the respondent declines to participate in the survey; and a residual "other" category (too infirm, inability to schedule a time, interviewer problems, etc.)" (Massey \& Tourangeau, 2013, p. 3). This is true whether the survey is web based or post.

Brick and Williams (2013) addressed the increase in non-responsiveness to surveys through their analysis of four surveys from $1996-2007$. They concluded that whether the survey was administered via telephone, electronically, or face-to-face, the reason most often associated with non-responsiveness was refusal to participate. This refusal may be due to lack of time or interest. However, the researchers suggested that “existing methods for modeling response mechanisms do not adequately explain" the 
increase in non-responsiveness. They conjectured further that people are being increasingly asked to complete surveys. They suggested simply that as more surveys are being sent to individuals, the refusal to comply may increase (2013).

It is important to note that low response rates do not indicate that a survey is not accurate. Fosnacht et al. (2017), for example, concluded that high response rates are not indicative of a change in the results, noting "Once researchers consider these results, they may spend less time worrying about achieving a high response rate and more time evaluating and using the data they collect" (p. 22). Moreover, it has been suggested that the number of responses is not the key factor in whether the data collected are valuable. Using the National Survey of Student Engagement (NSSE), this group found that although the size of the sampling affected the response rate, reliable data were still possible. Specifically, they suggested, "For smaller administrations, the response rate required for an estimate to be reliable was higher, but we found estimates to be increasingly reliable after receiving responses from 50 to 75 responses" (p. 16). They went on to say that researchers may want to focus more on improving the survey measurement tool or analyzing the data than using his/her efforts to increase response rate.

In 2018, Tai et al. randomly assigned groups to receive an email invitation to complete an online survey or a letter mailed to them with the survey link included. Both groups were sent a reminder in the same manner as the initial invitation. The response rate was higher for the individuals who were invited via email than by letter although the response rates in general were low: $34.8 \%$ for email and $25.8 \%$ for mailed letters. These rates were consistent with similarly conducted surveys. Another major finding was that 
older respondents were more willing to complete the survey than younger respondents, but the younger participants used the emailed invitation more than the older participants. Researchers have suggested that future research should be conducted on the design of the instrument and methodology to maximize response rates. "In sum, it is clear that response rates can be increased by spending more money, either indirectly by improving the design and implementation of the survey or directly by incentivizing respondents with monetary payments" (Massey \& Tourangeau, 2013, p. 230).

The overarching conclusion of current research is that response rate is not the most important outcome for electronic surveys, and that surveys with low response rates can and do provide valuable data. 


\section{CHAPTER 3}

\section{METHODS}

In this chapter, I describe the methods to be used to address the primary question and subquestions posed in this evaluation study, as noted below:

Research Question: What is the nature of students' perceptions of their learning experiences in a course delivered though a hybrid (blended) versus fully online instructional format?

\section{Participants}

Participants were students who had recently completed either a hybrid version of a fully online version of an introductory course on technology at a community and technical college. An initial pool of 394 possible participants was available. While basic demographic information for participants was collected during data collection, the population of the community and technical college generally consisted of a mix of firsttime college attendees and adult or non-traditional students who are returning to school or are career-switchers.

\section{Data Collection}

Design and data analysis. Given the dearth of research on comparing distance education learning environments, this is a pilot, descriptive evaluation study. I used an online survey delivered through the use of Qualtrics. Because students were sampled from existing courses of two different formats, some basic group comparisons were planned, though as noted below low response rates precluded statistical analyses of 
survey scale scores as planned. Based on recent course enrollments in the participating community college, I surveyed a total sample of 394 students (143 from hybrid sections of the course; 251 from fully online sections). The survey used was the Distance Education Learning Environments Survey (DELES; Walker \& Fraser, 2005), described briefly below. This survey results in seven scale scores: (1) Instructor Support, (2) Student Interaction and Collaboration, (3) Personal relevance, (4) Authentic Learning, (5) Active Learning, (6) Student Autonomy, and (7) Distance Education.

\section{Data Sources}

Demographic information. First, I collected very brief demographic information on participants (age, gender, and ethnicity), as well as limited information (a single item) on their prior experience with technology in coursework or employment.

Student perceptions - survey instrument. Second, participants completed the 34 items that make up the DELES; this is described in detail below.

Student perceptions - researcher-developed items. Finally, in order to potentially elucidate or illustrate key findings or patterns of responding on the DELES, I included three researcher-developed Likert-scale items, as well as one open-ended question regarding participants' experiences in their course. Specifically, I asked participants to rate their agreement with three Likert-scale items regarding their perceptions of whether their knowledge and ability to use content increased as a result of the course. The one open-ended question was designed to assess perceptions of the course delivery format specifically (i.e., What aspects of the way this course was delivered impacted your success, either positively or negatively?). 


\section{The Distance Education Learning Environments Survey (DELES)}

Walker and Fraser (2004) created and have since validated the DELES as a means to evaluate the psychosocial environment in post-secondary distance education learning contexts. The survey consists of 34 items in seven areas:

1. Instructor Support

2. Student Interaction and Collaboration

3. Personal Relevance

4. Authentic Learning

5. Active Learning

6. Student Autonomy

7. Distance Education

The development of the DELES was based on earlier work by Fraser (1986) and Jegede, Fraser, and Fisher (1998), and involved (a) an examination of all then-existing instruments assessing learning environments to scan for appropriate constructs, (b) the development and pilot testing of an initial scale, and (c) a series of studies designed to establish basic psychometric properties (i.e., internal consistency) and factor structure. Walker and Fraser (2004) also took into account Moos' (1974) theory of social organization dimensions of human environments; these included the Relationship Dimension, the Personal Development Dimension, and the System Maintenance and Change Dimension. By 2015, Fernandez-Pascual, Ferrer-Cascales, Reig-Ferrer, Albaladejo-Blazquez, and Walker reported that "The original DELES has been used in at least 27 independent studies with strong reliability and validity.” (p. 1387) 


\section{Procedures}

Data collection for this study was conducted exclusively through an online survey using Qualtrics. Following IRB approval at both institutions, staff at the participating institution, Jefferson Community and Technical College, sent the survey link to potential participants, which included all students who have completed any section of either of the courses listed above during the period Fall 2016 through Fall 2017. The Coordinator of Institutional Research at Jefferson Community and Technical College agreed to extract and prepare two such email lists - one for students from the hybrid sections, and one for students from the fully online sections so that the survey could be sent separately to the two groups. I then merged the resulting data produced by the two forms of the survey into a single file for analysis, adding a single binary data element to indicate whether the data reflect responses from the online or blended format group.

As noted above, participants received an email message inviting them to participate, with the link to the survey embedded in the email. Participants who clicked on the survey link first saw the preamble (attached) describing the nature of the survey and this study, and explaining their rights. They were asked to click yes or no to indicate whether they consented to participate; clicking yes began the actual survey. Clicking no did not allow potential participants to continue with the survey.

\section{Measures}

The three elements of the survey included the following: demographics, the DELES survey itself, and the three researcher-developed items. 
Demographics. Demographic information on participants (age, gender, and ethnicity), as well as limited information (a single item) on their prior experience with technology in coursework or employment.

DELES. The 34-item DELES survey.

Researcher-developed items. Three researcher-developed Likert-scale items, as well as one open-ended question regarding their experiences in their course. The three Likert-scale items were rated as $1=$ strongly disagree, $2=$ disagree, $3=$ agree, $4=$ strongly agree.

1. My knowledge of Microsoft Office increased as a result of this course.

2. My ability to use Microsoft Office components (e.g., Word, Excel, PowerPoint, and Access) increased as a result of this course.

3. This class has positively impacted my use of Microsoft Office in my work place.

The open-ended item was "What aspects of the way this course was delivered impacted your success, either positively or negatively."

\section{Description of Course Sections}

Hybrid sections of the course targeted here were offered with 1.25 hours in class and the remaining work done outside of class. The hybrid sections provided both synchronous and asynchronous learning. The online section were asynchronous with no scheduled time to be in class. The students self-selected which section to enroll in.

All sections used the same textbook, computer software, and Blackboard Learning Management System (LMS). The students in the online section used a second learning management system - MindTap, an interactive learning system developed by Cengage 
Learning, further utilizes a more specific Skills Assessment Manager (SAM), which is a tool used specifically to help students "master Microsoft Office and computer concepts essential to academic and career success. Students observe, practice, and train, then apply their skills live in the application" (MindTap, n.d.). SAM includes automatically graded assignments and a variety of reporting tools designed to provide efficiency and ease of use for instructors. MindTap is accessed through Blackboard via a link to the specific class on the Cengage website. (MindTap and SAM will be referred to hereafter as MindTap of ease of reporting). All sections had access to the same materials in Blackboard and took the same quizzes via Blackboard for each topic. The exams and assignments were somewhat different as the online section utilizes the assignments and exams offered through MindTap.

\section{Key Distinctions between Hybrid and Online Sections}

The key distinctions between the online and hybrid sections are described in the paragraphs that follow, and are summarized in Table 1.

Hybrid Section. Students in the hybrid section had access to PowerPoints for each tutorial provided by the publisher. The students had teacher-led instruction over the material during the 1.25 hour in-class time each week. The students also had access to videos, notes, other instructional material added to Blackboard by the instructor. The students had access to a printed textbook or etext that they could rent or purchase.

Online Section. In the online section, supported by MindTap, the unit consists of one reading activity and three SAM activities. The students had access to SAM Training Excel Tutorial 1, SAM Exam Excel Tutorial 1, and SAM Project Excel Tutorial 1. The video guidance provided to students within the online package states "SAM Training 
provides you with self-paced practice in a simulated environment. SAM Exams are interactive assessments that evaluate your understanding of Microsoft Office skills. With SAM Projects, you work directly in Microsoft Office to complete real-world cases."

(MindTap, n.d.)

\section{Table 1}

Key Distinctions between Hybrid And Online Sections

\begin{tabular}{|c|c|c|}
\hline & Hybrid section & Online section \\
\hline Assignments & $\begin{array}{l}\text { Case problems from text. One } \\
\text { submission allowed but do some } \\
\text { of work in class together. }\end{array}$ & $\begin{array}{l}\text { Exams in MindTap that count as } \\
\text { assignment. Three attempts } \\
\text { allowed. There are simulation } \\
\text { based. }\end{array}$ \\
\hline Blackboard Materials & $\begin{array}{l}\text { Resources I have downloaded } \\
\text { from the publisher, gathered, or } \\
\text { created. }\end{array}$ & $\begin{array}{l}\text { Resources I have downloaded } \\
\text { from the publisher, gathered, or } \\
\text { created. }\end{array}$ \\
\hline Discussion Board & $\begin{array}{l}\text { Not required of students. } \\
\text { Students are encouraged to post } \\
\text { questions to the professor and } \\
\text { other students are allowed to } \\
\text { respond. }\end{array}$ & $\begin{array}{l}\text { Not required of students. } \\
\text { Students are encouraged to post } \\
\text { questions to the professor and } \\
\text { other students are allowed to } \\
\text { respond. }\end{array}$ \\
\hline Exams & $\begin{array}{l}\text { Exam } 1 \text { - Testbank } \\
\text { Remaining exams - application } \\
\text { based. Material is chosen from } \\
\text { instructor resources provided by } \\
\text { textbook publisher. }\end{array}$ & $\begin{array}{l}\text { Exam } 1 \text { - Testbank } \\
\text { Remaining exams - Capstone } \\
\text { Projects in MindTap }\end{array}$ \\
\hline $\begin{array}{r}\text { Learning Management } \\
\text { System \#1 }\end{array}$ & Blackboard & Blackboard \\
\hline 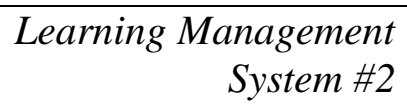 & N/A & MindTap by Cengage \\
\hline
\end{tabular}




$\begin{array}{rll}\text { Online Chat } & \begin{array}{l}\text { Using Blackboard Collaborate, } \\ \text { students are able to use online } \\ \text { chat including screen sharing to } \\ \text { demonstrate using the software. }\end{array} & \begin{array}{l}\text { Using Blackboard Collaborate, } \\ \text { students are able to use online } \\ \text { chat including screen sharing to } \\ \text { demonstrate using the software. }\end{array}\end{array}$

\begin{tabular}{rll}
\hline $\begin{array}{r}\text { Practice and Training } \\
\text { Materials }\end{array}$ & $\begin{array}{l}\text { Review and case problems in the } \\
\text { textbook. }\end{array}$ & $\begin{array}{l}\text { Practice projects and review in } \\
\text { MindTap. }\end{array}$ \\
\hline Quizzes & Testbank questions & Testbank questions \\
\hline
\end{tabular}

\section{Data Analysis}

As this is a pilot, descriptive evaluation study, I was interested primarily in describing students' perceptions of their course experiences. However, given that two distinct groups of students completed the survey (those in the fully online versus hybrid/blended versions of the course), some basic comparisons were planned; as noted below, due to low response rates, these statistical analyses were not possible. Because of this, I summarize descriptive statistics on the DELES survey's seven scale scores.

To triangulate what might be evident in the DELES responses, I analyzed narrative responses to the open-ended questions using standard qualitative data analysis methods. I first coded responses by category, sought to identify themes, looked for commonalities and differences within and across groups, and tried to examine whether and how open-ended responses added to or contradicted DELES responses. 


\section{CHAPTER 4}

\section{RESULTS}

\section{Introduction}

The primary focus of this pilot, descriptive evaluation study was to describe students' perceptions of their course experiences within two distinct groups of students who participated in either a fully online or a hybrid/blended version of an introductory course). The two groups surveyed differed in the course format (hybrid versus online group) and the outcome variable of primary interest included the seven scale scores on the Distance Education Learning Environments Survey (DELES) (Walker \& Fraser, 2004). Results are presented as they pertain to the question posed, drawing from the data sources used for this study.

\section{The Research Question}

What is the nature of students' perceptions of their learning experiences in a course delivered though a hybrid (blended) versus fully online instructional format as measured by the Distance Education Learning Environments Survey (DELES)? (Walker \& Fraser, 2004)

a. Measures

1. Demographic information on participants (age, gender, and ethnicity), as well as limited information (a single item) on their prior experience with technology in coursework or employment.

2. The 34-item DELES survey. 
3. Three researcher-developed Likert-scale items, as well as one open-ended question regarding their experiences in their course: (1 = strongly disagree, 2 = disagree, $3=$ agree, $4=$ strongly agree) .

a. My knowledge of Microsoft Office increased as a result of this course.

b. My ability to use Microsoft Office components (e.g., Word, Excel, PowerPoint, and Access) increased as a result of this course.

c. This class has positively impacted my use of Microsoft Office in my work place.

\section{Table 2}

Number of Participants Who Completed DELES Survey

\begin{tabular}{lr}
\hline Instructional format & Number of Survey Completers \\
\hline Hybrid & 9 \\
Online & 46 \\
\hline
\end{tabular}

\section{Demographic Data}

Survey participants were enrolled in a computer literacy course taught by the same instructor during the Fall 2016 - Fall 2017 semesters. Each participant was invited to complete the DELES survey via Qualtrics. The students were invited to participate via email from the Jefferson Community and Technical College Director of Institutional Effectiveness, Research, \& Planning. The students were sent an initial email and followup emails by the Director. 
The demographic data gathered included age, gender, ethnicity, and a question regarding experience or prior training with technology with additional space for a response. The four options to the experience or prior training with technology were:

1. at least one high school class that focuses specifically on technology (e.g., keyboarding, computer technology).

2. at least one high school class in which the teacher made extensive use of technology (computer use, internet applications).

3. a post-secondary course on technology (prior to the current course).

4. an employment-based training on some aspect or application of technology. If so, please describe in the box below.

\section{Table 3}

Age of Participants Who Completed DELES Survey by Modality

\begin{tabular}{lrrrrrr}
\hline & \multicolumn{3}{c}{ Online } & & \multicolumn{2}{c}{ Hybrid } \\
& $n$ & Mean & $\begin{array}{c}\text { Standard } \\
\text { Deviation }\end{array}$ & $n$ & Mean & Standard \\
Age & 46 & 31.45 & 12.29 & 9 & 20.00 & 0.58 \\
\hline
\end{tabular}

In online group, the age varied widely as shown by the mean of 31.45 and standard deviation of 12.29. For the hybrid group, the ages of the students were similar with a mean of 20 and a standard deviation of 0.58 . The students self-selected which course delivery mode to enroll in. 


\section{Table 4}

Demographic Data for Participants Who Completed DELES Survey by Modality

\begin{tabular}{|c|c|c|c|c|c|}
\hline & & \multicolumn{2}{|c|}{ Online } & \multicolumn{2}{|c|}{ Hybrid } \\
\hline & & $n$ & $\begin{array}{c}\text { Column } \\
\text { Valid N \% }\end{array}$ & $n$ & $\begin{array}{c}\text { Column } \\
\text { Valid N \% }\end{array}$ \\
\hline \multirow{3}{*}{ Gender } & & 8 & $17.4 \%$ & 0 & $0.0 \%$ \\
\hline & Female & 22 & $47.8 \%$ & 6 & $66.7 \%$ \\
\hline & Male & 16 & $34.8 \%$ & 3 & $33.3 \%$ \\
\hline \multirow{5}{*}{ Ethnicity } & Asian & 1 & $17.4 \%$ & 0 & $0.0 \%$ \\
\hline & $\begin{array}{l}\text { Black or } \\
\text { African }\end{array}$ & & & & \\
\hline & American & 3 & $2.2 \%$ & 0 & $0.0 \%$ \\
\hline & Other & 3 & $6.5 \%$ & 0 & $0.0 \%$ \\
\hline & White & 31 & $67.4 \%$ & 9 & $100.0 \%$ \\
\hline
\end{tabular}

The majority of students in the hybrid group was female (66.6\%); while more students in the online groups reported gender as female (47.8\% compared to $34.8 \%$ male), it was noted that $17.4 \%$ of students in this group did not indicate gender. Students in the online group reported as white (67.4\%), and $100 \%$ of the students in the hybrid section identified as white.

\section{Table 5}

Experience or Prior Training Data for Participants Who Completed DELES Survey by Modality

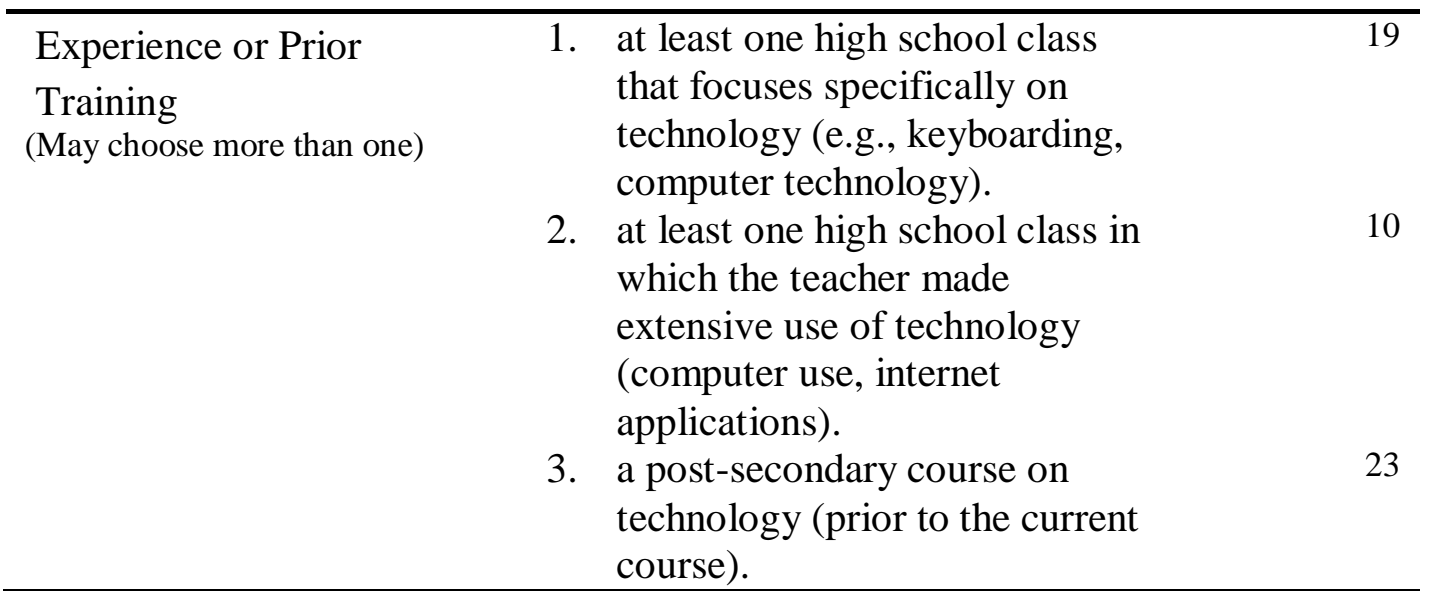


4. an employment-based training

on some aspect or application

of technology. If so, please

describe in the box below.

Participants were asked to select any of the four options relating to experience and prior training that applied to them. The highest number, $42.5 \%$, reported to have taken $a$ post-secondary course on technology (prior to the current course). Students who reported having an employment-based training on some aspect or application of technology was the smallest percentage at $14.8 \%$.

\section{Data Analysis Procedures}

Given (a) the descriptive purpose of this evaluation study, and (b) the small response rate among the hybrid/blended course group $(n=9)$, statistical comparisons between the two groups are not warranted. Thus, I report descriptive statistics for each item on the DELES, along with descriptives for total scores by scale. Despite limitations in statistical power to test for difference in means, and because potential differences in patterns of responding across groups seemed evident for some scales, I also present box and whisker plots for each scale by group. As noted by Valentine et al. (2015), even in the absence of power for traditional analyses, these descriptives and the graphic display of means and the spread of scores may offer at least some insight into potential differences, and in particular point to avenues for potential further research and exploration.

Narrative responses to the open-ended question were analyzed using standard qualitative data analysis methods; I coded responses by category, sought to identify themes, and looked for commonalities and differences within and across groups. The categories emerged from repeating trigger words in the comments: instructor, learning 
management system, course design, employment and skills, and course delivery method. I examined positive and negative responses in each category.

In addition to looking for themes I assessed the extent to which themes fit into, or expanded upon, the categories already provided and assessed by the quantitative survey items (i.e., Instructor Support, Student Interaction and Collaboration, etc.). Finally, acknowledging that establishing statistical significance in any differences observed between the two groups' rating scale response would not be possible, due to small group sizes, I attempted to make sense of any observed differences in means between the two groups by mapping these onto the themes that emerged from qualitative analysis of the open ended responses.

The $n$ for each group in the demographic data gathered is higher than the $n$ for each of the DELES Scales. If a participant did not complete the entire survey, their responses were not counted in the scale data.

\section{Table 6}

\section{Constructs Measured by DELES}

\begin{tabular}{lc}
\hline Construct & Number of Items \\
\hline Instructor Support & 8 \\
Student Interaction and Collaboration & 6 \\
Personal Relevance & 7 \\
Authentic Learning & 4 \\
Active Learning & 3 \\
Student Autonomy & 8 \\
Distance Education & 5 \\
\hline Total Items & 41 \\
\hline
\end{tabular}




\section{Table 7}

DELES Scale 1: Instructor Support

\begin{tabular}{|c|c|c|c|c|c|c|}
\hline & \multicolumn{3}{|c|}{ Online } & \multicolumn{3}{|c|}{ Hybrid } \\
\hline & Valid N & Mean & $\begin{array}{l}\text { Standard } \\
\text { Deviation }\end{array}$ & Valid N & Mean & $\begin{array}{l}\text { Standard } \\
\text { Deviation }\end{array}$ \\
\hline DELES_1 & 33 & 3.45 & 1.00 & 8 & 3.13 & 1.36 \\
\hline DELES_2 & 32 & 3.28 & 1.30 & 8 & 3.00 & 1.41 \\
\hline DELES_3 & 32 & 3.47 & .98 & 8 & 2.88 & 1.64 \\
\hline DELES_4 & 32 & 3.00 & 1.37 & 8 & 2.88 & 1.55 \\
\hline DELES_5 & 32 & 3.41 & 1.19 & 8 & 2.88 & 1.64 \\
\hline DELES_6 & 32 & 3.34 & 1.15 & 8 & 2.63 & 1.69 \\
\hline DELES_7 & 32 & 3.69 & .82 & 8 & 2.75 & 1.58 \\
\hline DELES_8 & 32 & 2.91 & 1.40 & 8 & 3.00 & 1.60 \\
\hline Instructor Support & 32 & 26.56 & 8.31 & 8 & 23.13 & 12.04 \\
\hline
\end{tabular}

The highest mean for the hybrid group for Instructor Support indicated the instructor found time to respond (mean 3.13, $\mathrm{SD}=1.36$ ), whereas the lowest mean was associated with instructor encouragement (mean $=2.63, \mathrm{SD}=1.69)$.

For the online group, the highest mean $($ mean $=3.69, \mathrm{SD}=0.82)$ indicated the instructor was easy to contact. Positive/negative feedback provided by instructor was identified as the lowest mean for this group (mean $=2.91, \mathrm{SD}=1.40)$. 


\section{Table 8}

DELES Scale 2: Student Interaction and Collaboration

\begin{tabular}{|c|c|c|c|c|c|c|}
\hline & & Online & & & Hybrid & \\
\hline & Valid N & Mean & $\begin{array}{l}\text { Standard } \\
\text { Deviation }\end{array}$ & Valid N & Mean & $\begin{array}{l}\text { Standard } \\
\text { Deviation }\end{array}$ \\
\hline DELES_9 & 32 & 2.19 & 1.38 & 8 & 2.63 & 1.19 \\
\hline DELES_10 & 32 & 2.00 & 1.39 & 8 & 2.13 & 1.25 \\
\hline DELES_11 & 32 & 1.84 & 1.37 & 8 & 1.75 & 1.49 \\
\hline DELES_12 & 32 & 1.84 & 1.42 & 8 & 2.13 & 1.46 \\
\hline DELES_13 & 32 & 1.53 & 1.44 & 8 & 2.38 & 1.06 \\
\hline DELES_14 & 32 & 1.66 & 1.41 & 8 & 2.13 & 1.25 \\
\hline $\begin{array}{l}\text { Student } \\
\text { Interaction/ } \\
\text { Collaboration }\end{array}$ & 32 & 11.06 & 7.51 & 8 & 13.13 & 6.47 \\
\hline
\end{tabular}

Both groups indicated low interaction/collaboration rates with the online section having the lowest mean $($ mean $=1.53, \mathrm{SD}=1.44)$ related to collaboration with others in the class. The lowest mean for the hybrid group indicated that work was seldom shared in the class $($ mean $=1.75, \mathrm{SD}=1.49)$. Although collaboration was not a requirement in the course, the online and hybrid groups rated working with others in the class highest hybrid group $($ mean $=2.63, \mathrm{SD} 1.19)$ and the online group $($ mean $=2.19, \mathrm{SD}=1.38)$.

\section{Table 9}

DELES Scale 3: Personal Relevance

$\begin{array}{cccccc} & \text { Online } & & & \text { Hybrid } & \\ \text { Valid N } & \text { Mean } & \text { Standard } & \text { Valid N } & \text { Mean } & \text { Standard } \\ & & \text { Deviation } & & & \text { Deviation }\end{array}$




\begin{tabular}{lcccccc}
\hline DELES_15 & 32 & 2.97 & .90 & 7 & 2.71 & 1.50 \\
DELES_16 & 32 & 3.28 & .77 & 7 & 3.14 & 1.46 \\
DELES_17 & 32 & 2.88 & .98 & 7 & 2.86 & 1.57 \\
DELES_18 & 31 & 2.77 & 1.12 & 7 & 2.57 & 1.40 \\
DELES_19 & 32 & 2.94 & 1.05 & 7 & 2.43 & 1.27 \\
DELES_20 & 32 & 3.34 & .70 & 7 & 2.71 & 1.60 \\
DELES_21 & 32 & 3.19 & .78 & 7 & 2.14 & 1.35 \\
Personal Relevance & 31 & 21.61 & 4.82 & 7 & 18.57 & 9.69 \\
& & & & & &
\end{tabular}

The online group chose learning things about the world outside the university as the highest personal relevance area (mean $=3.34, \mathrm{SD}=.70$ ) while the hybrid group chose the most personally relevant as being able to pursue topics of interest to them $($ mean $=$ $3.14, \mathrm{SD}=1.46$ ). The groups differed in reporting their personal experiences in the class. The online group indicated that they were less likely to apply everyday experiences in class (mean $=2.77, \mathrm{SD}=1.12$ ). The hybrid group felt that they did not apply out-of-class experience in the class (mean $=2.14, \mathrm{SD}=1.35)$.

Table 10

DELES Scale 4: Authentic Learning

\begin{tabular}{lrrrrrrr}
\hline & & Online & & & Hybrid & \\
& Valid N & Mean & $\begin{array}{c}\text { Standard } \\
\text { Deviation }\end{array}$ & Valid N & Mean & $\begin{array}{c}\text { Standard } \\
\text { Deviation }\end{array}$ \\
\hline DELES_22 & 32 & 2.63 & 1.13 & 7 & 2.14 & 1.07 \\
DELES_23 & 32 & 3.16 & .88 & 7 & 2.86 & 1.07
\end{tabular}




$\begin{array}{lrrrrrr}\text { DELES_24 } & 32 & 3.22 & .71 & 7 & 3.00 & 1.00 \\ \text { DELES_25 } & 31 & 3.16 & .78 & 7 & 3.00 & .82 \\ \text { DELES_26 } & 31 & 3.10 & .83 & 7 & 3.00 & .82 \\ \text { Authentic Learning } & 31 & 15.23 & 3.78 & 7 & 14.00 & 4.04 \\ \end{array}$

Authentic learning in the class did not show much variation for the hybrid group. They indicated that work on assignments that deal with real world information and examples were the same (mean $=3, \mathrm{SD}=1,0.82$ and 0.82 ). The online group reported the highest mean $($ mean $=3.22, \mathrm{SD}=0.71)$ in working with assignments that deal with real world information. Neither group reported a high mean as to studying real cases relating to the class (hybrid: mean $=2.14, \mathrm{SD}=1.07$ and online: mean $=2.63, \mathrm{SD}=$ $1.13)$.

Table 11

DELES Scale 5: Active Learning

Online

Hybrid

Valid N Mean Standard Valid N Mean Standard
Deviation Deviation

\begin{tabular}{lcccccc}
\hline DELES_27 & 32 & 3.34 & .70 & 7 & 2.86 & 1.21 \\
DELES_28 & 32 & 3.44 & .62 & 7 & 3.14 & 1.21 \\
DELES_29 & 32 & 3.50 & .62 & 7 & 3.00 & 1.41 \\
Active Learning & 32 & 10.28 & 1.73 & 7 & 9.00 & 3.65
\end{tabular}

The highest mean and standard deviation for the online group as related to active learning was solving my own problems ( mean $=3.5, \mathrm{SD}=.62$ ). The hybrid group chose 
seek my own answers as the highest (mean $=3.14, \mathrm{SD}=1.21)$. Both groups ranked exploring their own learning strategies as the lowest mean (hybrid: mean $=2.86, \mathrm{SD}=$ 1.21 and online: mean $3.34, \mathrm{SD}=.7$ ).

\section{Table 12}

DELES Scale 6: Student Autonomy

\begin{tabular}{|c|c|c|c|c|c|c|}
\hline & & Online & & & Hybrid & \\
\hline & Valid N & Mean & $\begin{array}{l}\text { Standard } \\
\text { Deviation }\end{array}$ & Valid N & Mean & $\begin{array}{l}\text { Standard } \\
\text { Deviation }\end{array}$ \\
\hline DELES_30 & 32 & 3.56 & .67 & 7 & 3.29 & .76 \\
\hline DELES_31 & 32 & 3.38 & .75 & 7 & 3.14 & 1.46 \\
\hline DELES_32 & 32 & 3.59 & .71 & 7 & 3.71 & .49 \\
\hline DELES_33 & 32 & 3.75 & .51 & 7 & 3.86 & .38 \\
\hline DELES_34 & 32 & 3.50 & .76 & 7 & 3.71 & .49 \\
\hline Student autonomy & 32 & 17.78 & 2.88 & 7 & 17.71 & 2.63 \\
\hline
\end{tabular}

Student autonomy showed the highest mean and lowest means to be the same for each group. The hybrid group indicated that playing an important role in their learning ranked highest $($ mean $=3.86, \mathrm{SD}=.38)$ as did the online group $($ mean $=3.75, \mathrm{SD}=.51)$. As for the lowest mean, both groups indicated that working during time that they find convenient is the lowest indicator (hybrid: mean $=3.14, \mathrm{SD}=1.46$ and online: mean $=$ $3.38, \mathrm{SD}=.75)$. 


\section{Table 13}

DELES Scale 7: Distance Education

\begin{tabular}{lcccccc}
\hline & & Online & & & Hybrid & \\
& Valid N & Mean & $\begin{array}{c}\text { Standard } \\
\text { Deviation }\end{array}$ & Valid N & Mean & $\begin{array}{c}\text { Standard } \\
\text { Deviation }\end{array}$ \\
& 32 & 2.97 & .93 & 7 & 2.00 & 1.15 \\
\hline DELES_35 & 32 & 3.09 & .93 & 7 & 1.86 & 1.07 \\
DELES_36 & 32 & 3.00 & 1.08 & 7 & 2.14 & 1.21 \\
DELES_37 & 32 & 3.41 & .76 & 7 & 2.43 & 1.13 \\
DELES_38 & 32 & 3.09 & .89 & 7 & 2.14 & 1.07 \\
DELES_39 & 32 & 3.13 & .94 & 7 & 2.00 & 1.00 \\
DELES_40 & 32 & 2.78 & 1.16 & 7 & 1.57 & 1.13 \\
DELES_41 & 32 & 3.31 & 1.28 & 7 & 2.86 & 1.46 \\
DELES_42 & 32 & 24.78 & 6.23 & 7 & 17.00 & 8.49 \\
Distance Education & & & & & & \\
\hline
\end{tabular}

The question that scored the lowest mean for both groups was asking if the students would enjoy their education more if all their classes were online (hybrid: mean $=1.57, \mathrm{SD}=1.13$ and online: mean $=2.78, \mathrm{SD}=1.16$ ). The highest mean for the online group $($ mean $=3.41, \mathrm{SD}=.76)$ indicated that distance education was considered worth their time. The hybrid group was most satisfied with the class ( mean $=2.86, \mathrm{SD}=1.46$ ).

\section{Box and Whisker Plots of DELES Scales}

Although the small sample size precluded running statistical analyses as planned, I created box and whisker plots for each DELES scale to highlight that the differences between groups did vary across these scales. For some scales, the lack of differences 
between groups is clear, while for others the means and spread of scores seem to clearly favor one group over the other. In this section, I present box and whisker plots for each scale, contrasting the scores on each scale for the two subgroups of participants (online, hybrid). These plots are described briefly for each scale, and the implications of similarities and differences, both in terms of the present study and for future research, are discussed in Chapter 5.

Instructor Support. The box and whisker plots for DELES Scale 1, Instructor Support, appear in Figure 1 (see means in Table 7). Here it is evident that there was little overlap in scores across groups, with the online group rating instructor support as higher.

\section{Figure 1}

\section{DELES Scale 1: Instructor Support}

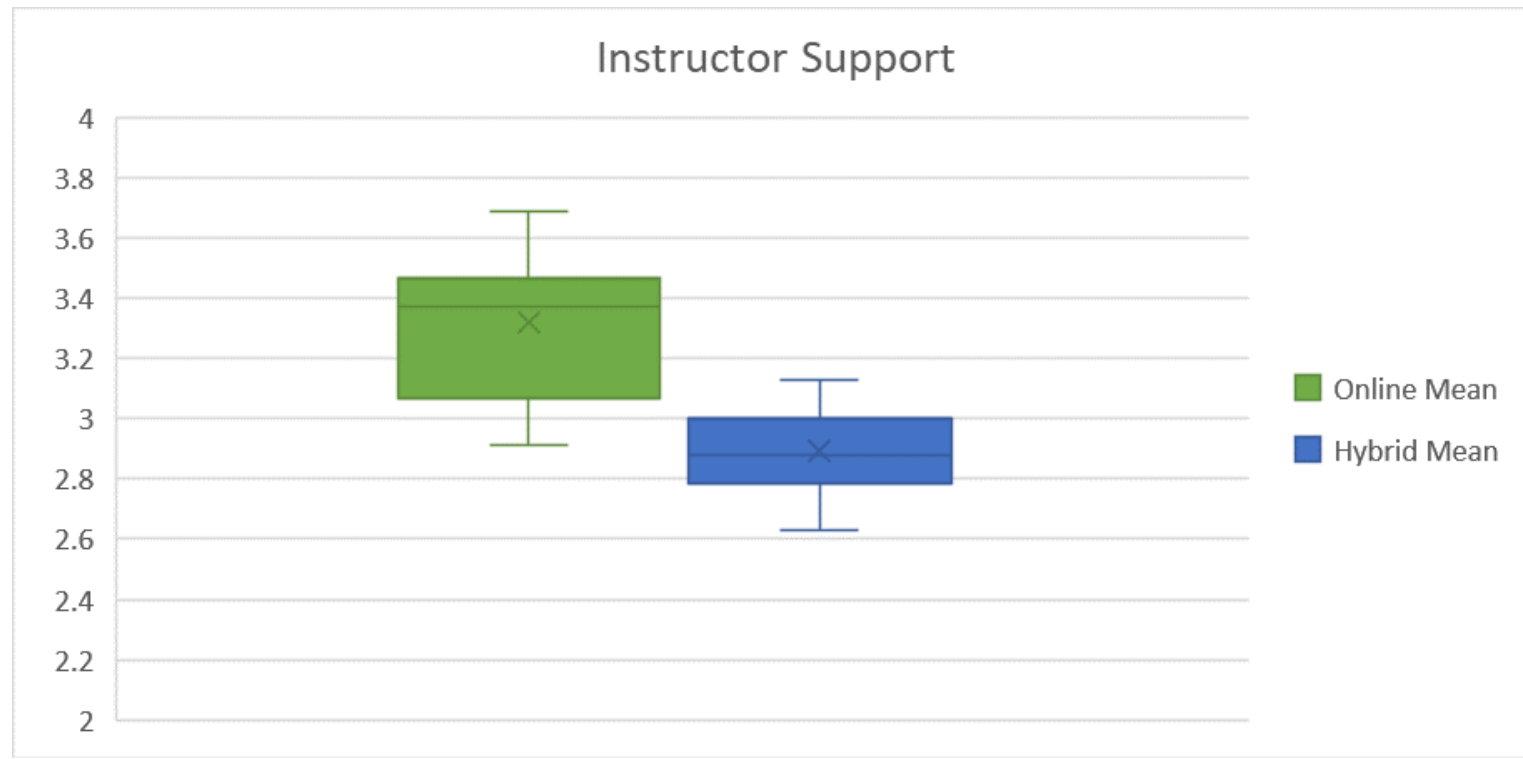

The spread of scores appearing to favor the online environment for this construct appears to stand in contrast to the qualitative comments offered by respondents. For example, one student in the blended learning environment stated, "It helped me to learn 
material from the professor in class, and then to come home and practice the material on my own."

Student interactions/collaboration. The box and whisker plots for DELES Scale 2, Student interaction/collaboration, appear in Figure 2 (see means in Table 8). As shown in Figure 2, while there is slight overlap in the middle $50 \%$ of scores, there may be indications of slightly higher ratings for the hybrid group. None of the students' qualitative comments addressed interaction or collaboration.

\section{Figure 2}

DELES Scale 2: Student Interaction/Collaboration

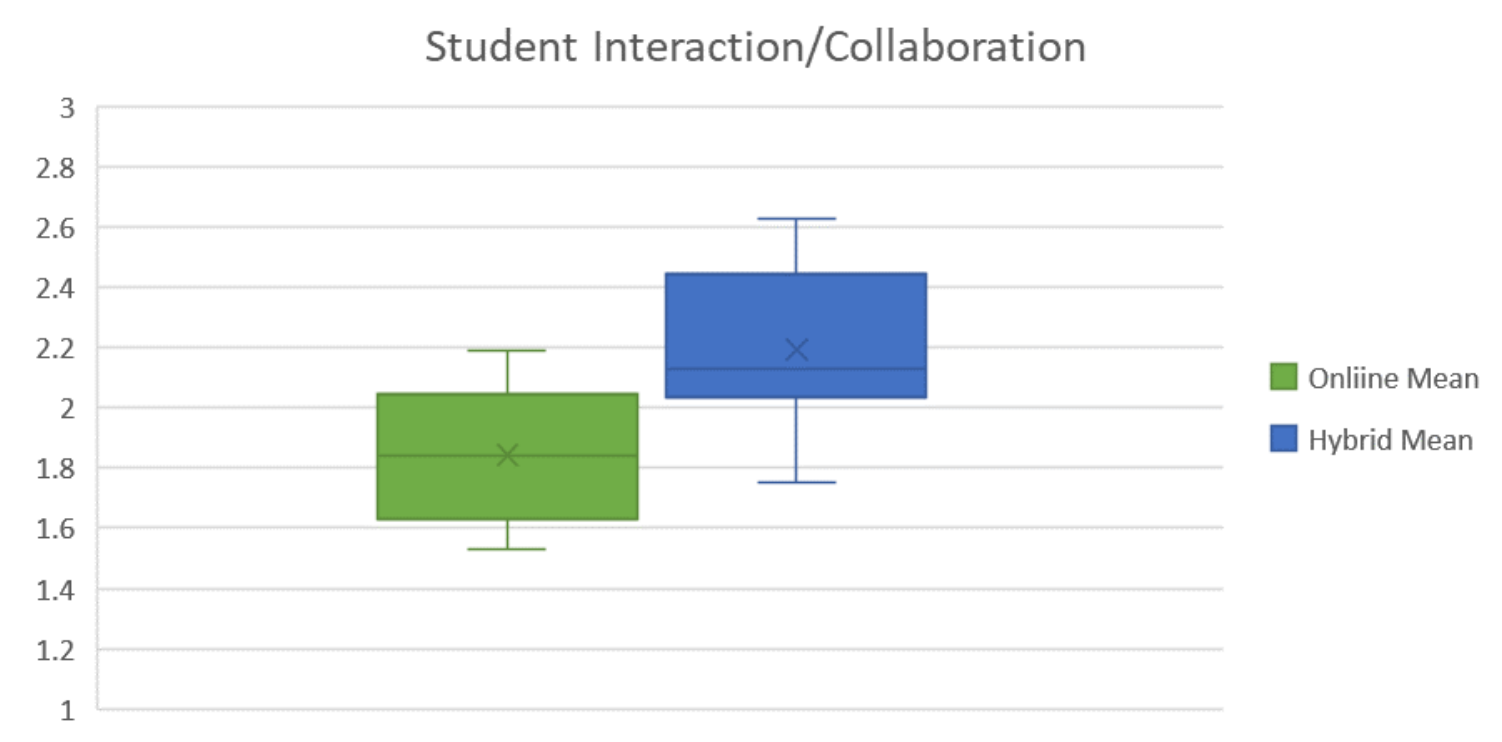

Personal relevance. The box and whisker plots for DELES Scale 3, Personal relevance, are presented in Figure 3 (see means in Table 9). From this plot it appears that the online group tended to rate the personal relevance of the course higher than did participants in hybrid courses. While there was some overlap between the two groups, the middle $50 \%$ of scores did not overlap for this scale. This was consistent with qualitative comments from the online group as well; several students in the online 
learning environment expressed that the material was applicable to their work environment; one stated, for example, "I use everything I learn at work every single day, making me a more valuable employee and a worthy competitor for advancement!"

\section{Figure 3}

DELES Scale 3: Personal Relevance

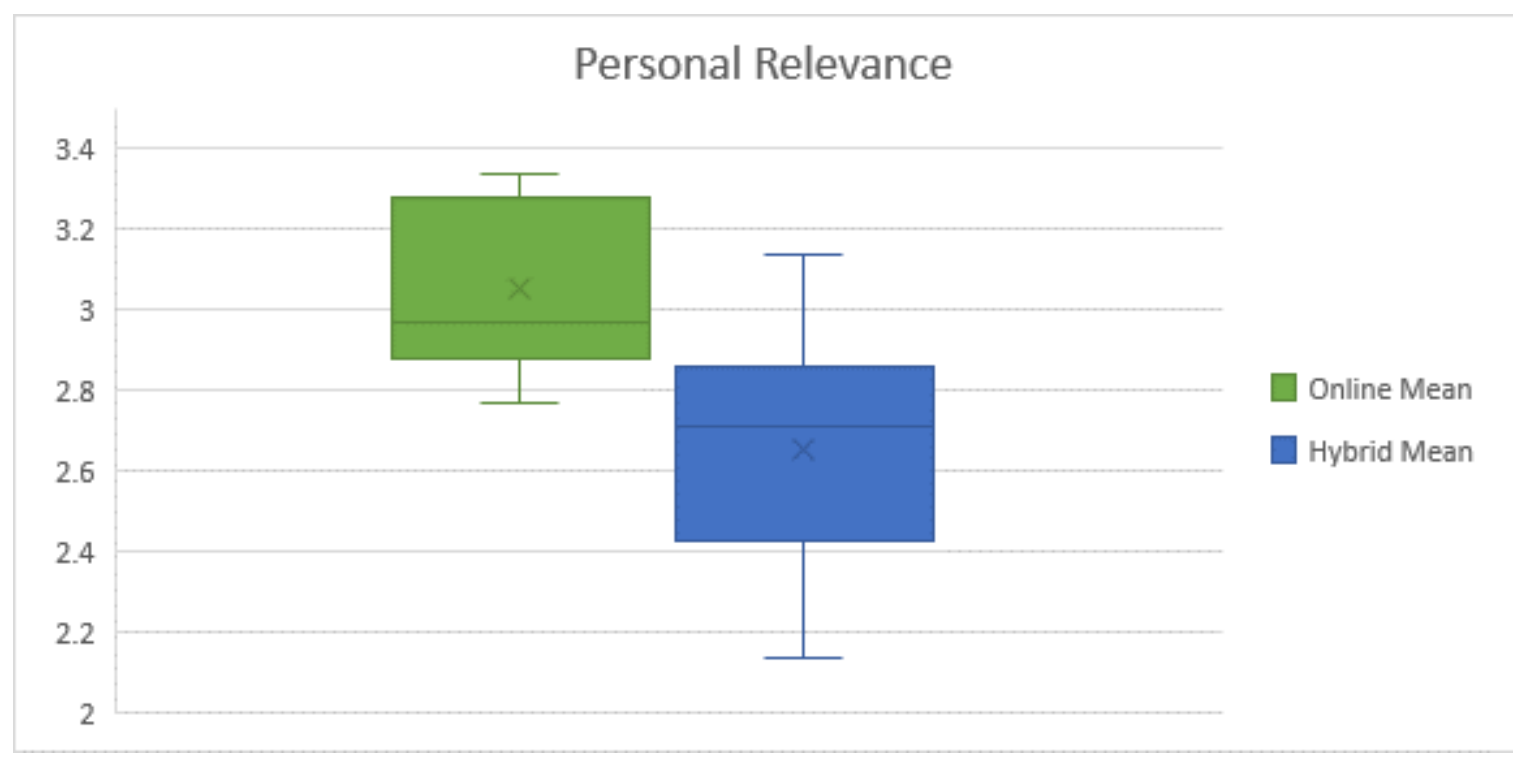

Authentic learning. The box and whisker plots for DELES Scale 4, Authentic learning, are presented in Figure 4 (see means in Table 10). Although there were some low scores among the hybrid group (indicated by the lower 'tail' in the plot for this group), overall these plots indicate a high degree of similarity in the responses of the two groups. This seems consistent with the mean of $15.23(\mathrm{SD}=3.78)$ for the online group and $14.00(\mathrm{SD}=4.04)$ for the hybrid group. 


\section{Figure 4}

\section{DELES Scale 4: Authentic Learning}

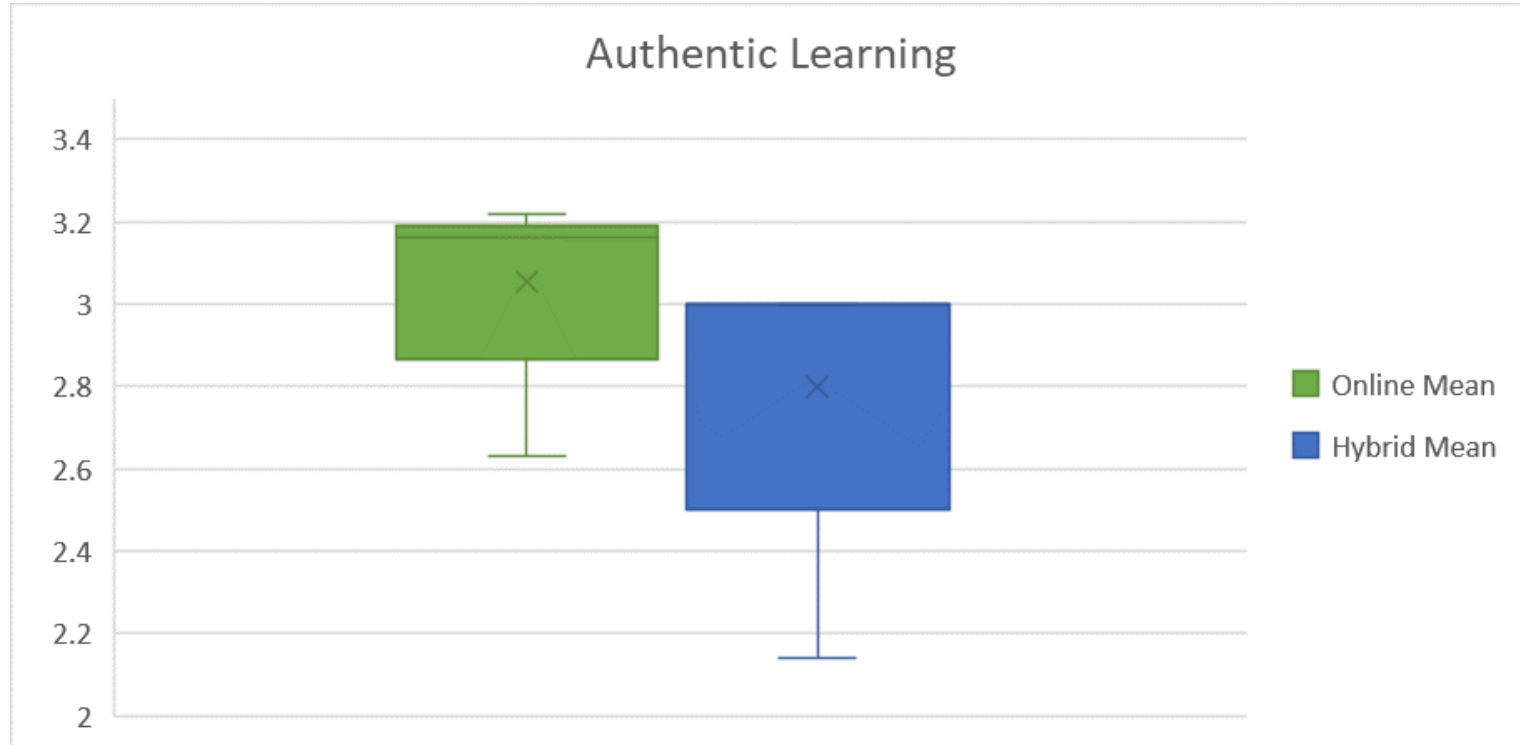

Active learning. As indicated in the box and whisker plots in Figure 5, the means and spread of scores for Active Learning appear to indicate a difference between groups, with the online group scoring higher. Although this scale consisted of only three items, thus reducing potential variability, the box plots show there was no overlap at all between the two groups on this scale. 


\section{Figure 5}

\section{DELES Scale 5: Active Learning}

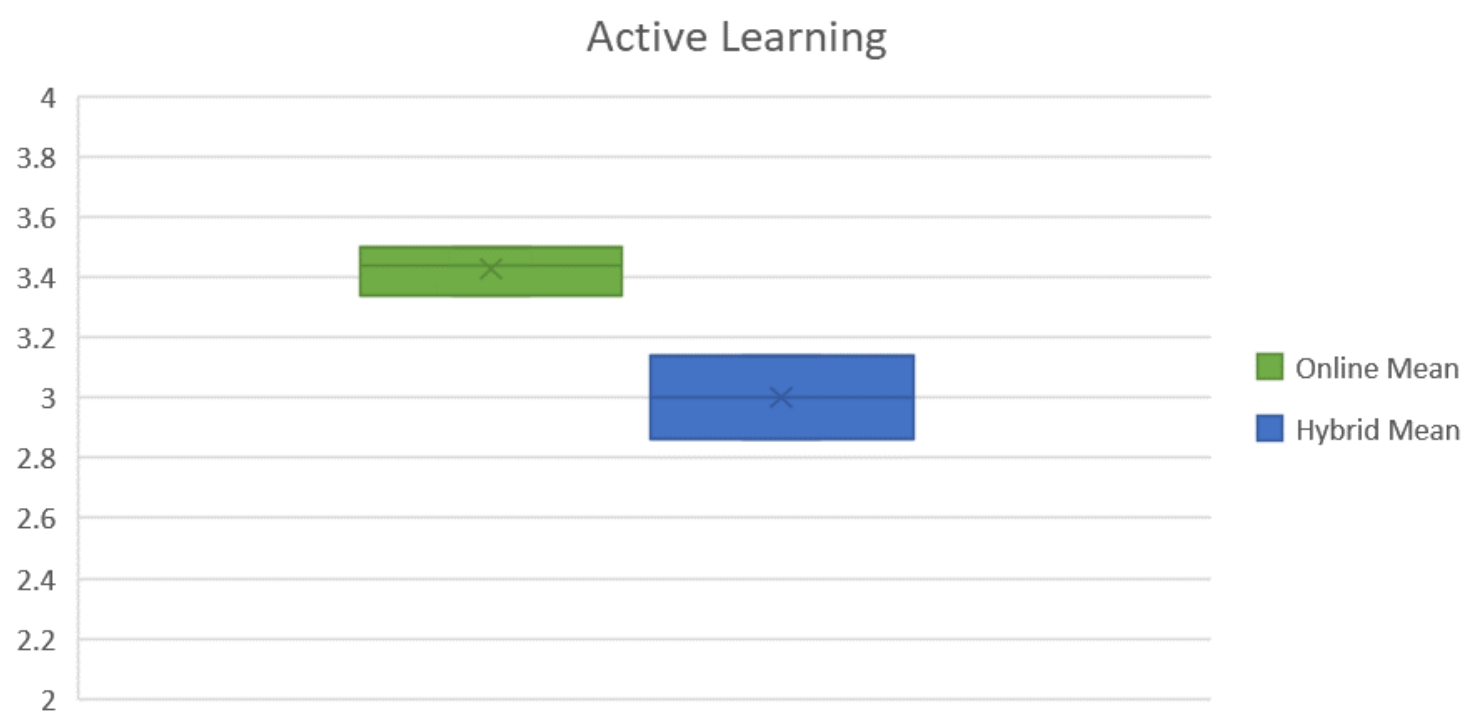

Student autonomy. As shown in Figure 6, the box plots for Scale 6, Student autonomy, indicate virtually complete overlap in scores, with the spread of scores for the online group contained entirely within the spread of scores for the hybrid group.

\section{Figure 6}

\section{DELES Scale 6: Student Autonomy}

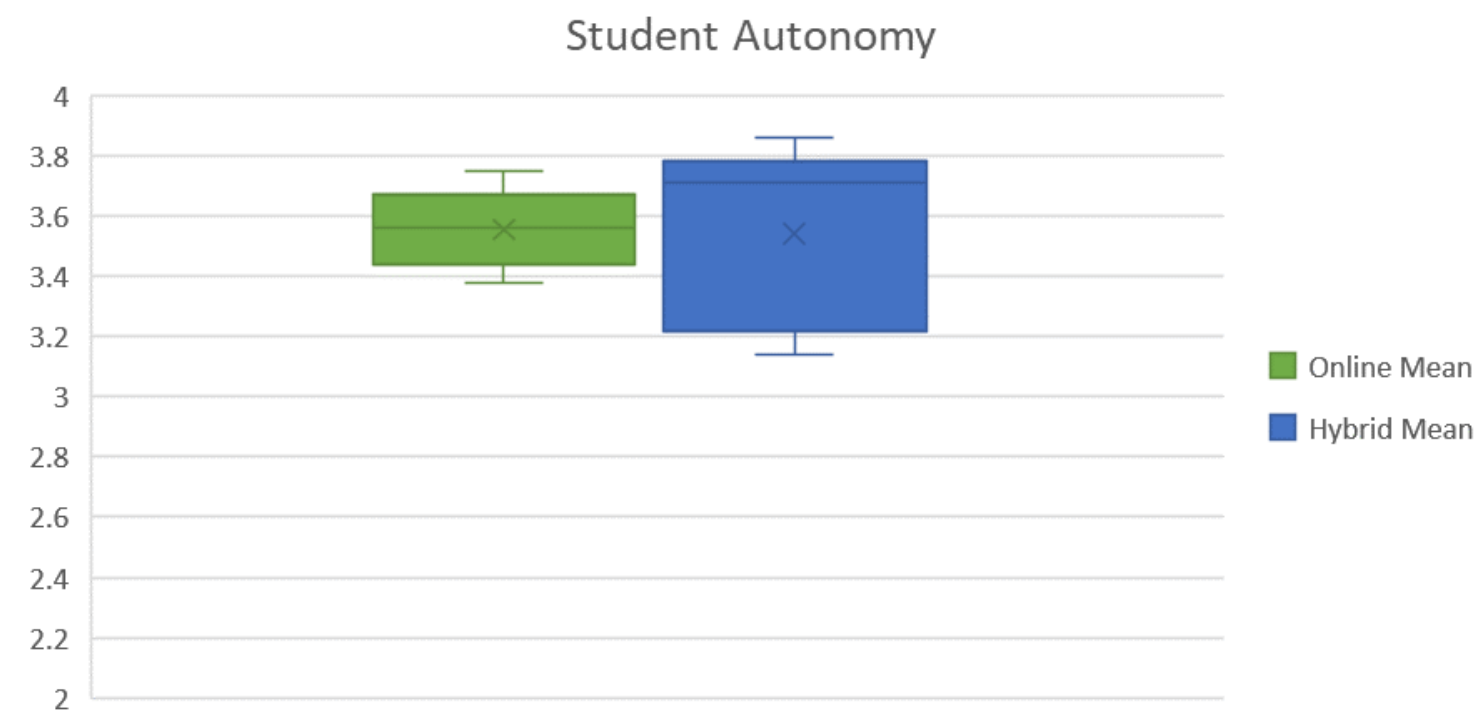


Distance education. Similar to the Active Learning scale (Scale 5), scores on DELES Scale 7, Distance Education also showed virtually no overlap between the groups, with the means and distribution of scores being higher for the online group. Perhaps importantly, the two items on this scale with the greatest mean differences between groups were "I prefer distance education," and "I look forward to learning by distance."

Figure 7

DELES Scale 7: Distance Education

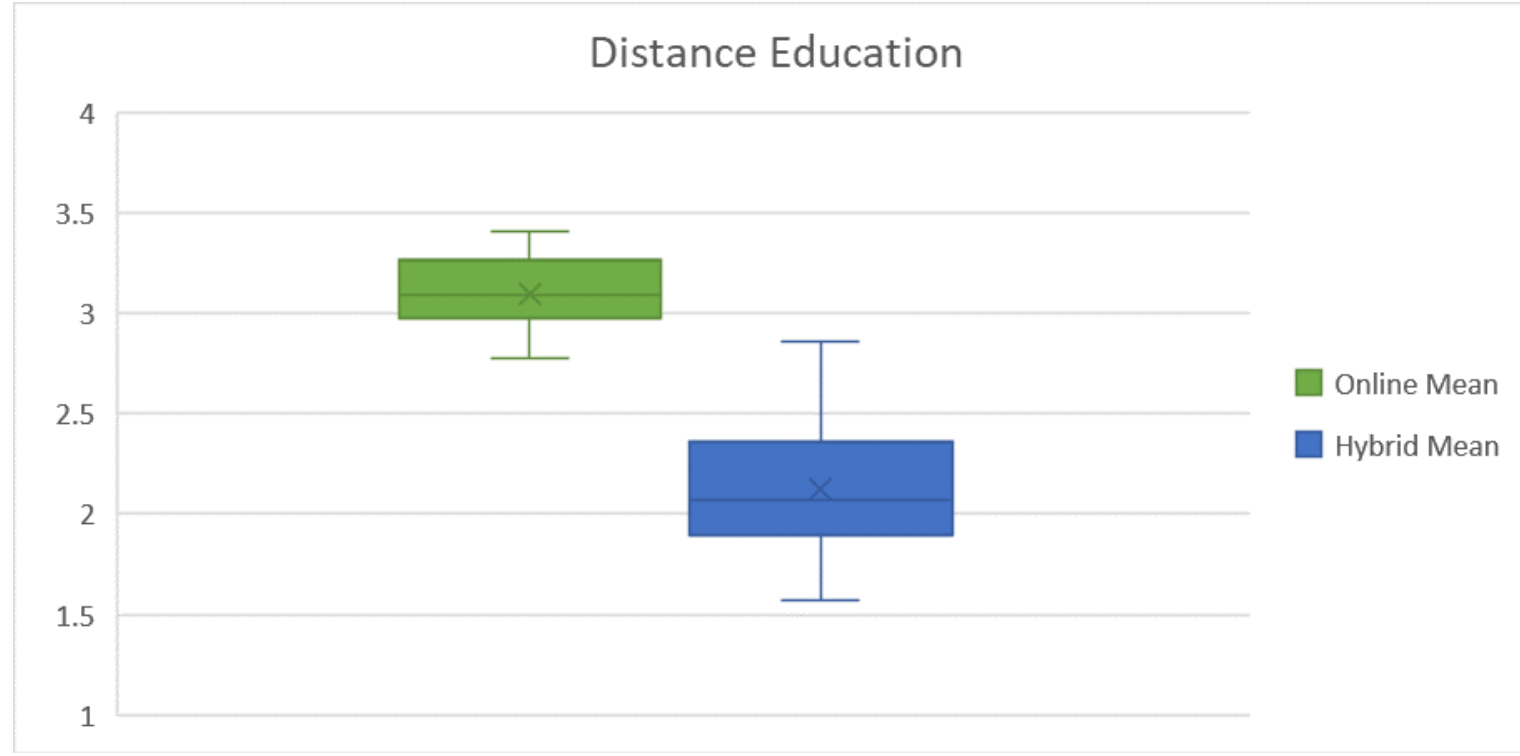

Qualitative Data. The researcher-developed open-ended question was intended to provide additional data that might help explain or elaborate upon the findings from the DELES. In analyzing the narrative responses to the open-ended question, I identified key concepts or phrases that were repeated using standard qualitative data analysis methods. The open-ended question is a single item designed to enhance this preliminary pilot descriptive study. I focused on responses that indicated categories, seeking to identify 
themes, and looking for commonalities and differences within and across groups (i.e. characteristics of the instructor, the course content, the delivery format, etc.)

I delved deeper into the responses to assess whether the response conveyed a positive, neutral, or negative tone. In the previous section, I included some of the comments listed below to triangulate the open-ended responses with the group means on the DELES scales. A complete listing of all qualitative comments, by group, is presented in Appendix F.

The hybrid group had six comments regarding course delivery. While one student indicated $i d k$ (I do not know), the others did offer substantive input. Five of the comments presented the instructor in a positive light stating instructor was available and helpful. One student commented negatively about the instructor.

The online group contributed 26 comments. Four students indicated that the instructor was a positive aspect to the course in communicating promptly and being helpful. One student described technical difficulties that the instructor was unable to resolve, thus putting the instructor in a negative light.

Two online students were not satisfied with the learning management system utilized - MindTap. Yet, others were appreciative of the way the learning management system presented the material. A few students mentioned working full time and feeling that online classes were the best and only option to be able to attend college.

Five students spoke to the course design in a positive manner. The tasks were divided evenly throughout the semester, and being walked through the material was effective. 
Four online students referenced employment and skills needed to progress at work as a positive outcome. One student reported the course objectives and material to be redundant, but can see how this would positively impact their life especially when looking for jobs.

Out of the 26 comments, 10 were directly pointed to course delivery method. The students reported that being able to take the class online allowed them the flexibility to complete assigned tasks when their time permitted indicating this was a positive experience.

Overall, the responses were positive toward the online delivery method although there was some discussion regarding the learning management system. The hybrid group showed in their responses that the instructor played an important role in the delivery method and student success. 


\section{CHAPTER 5}

\section{DISCUSSION}

\section{Introduction}

In this section, I interpret the findings of this study by examining students' responses across the seven scales of the DELES, including discussing how their openended responses fit into, complement, or contradict the themes and concepts evident in these scales. I also consider how these findings support, contradict, or add to the current literature on student perceptions of their learning environments. These are organized by DELES scale.

\section{The Research Question}

What is the nature of differences in students' perceptions of their learning experiences in a course delivered though a hybrid (blended) versus fully online instructional format as measured by the Distance Education Learning Environments Survey (DELES)? (Walker \& Fraser, 2004)

\section{Demographics}

There was little diversity in the hybrid group. The students self-identified as white with a mean age of 20 . The majority of students were female. This is probably a very important element of the current study, for several reasons. First, it may suggest that students self-selecting into a hybrid section may be much more likely to of a certain demographic; they were generally white females, about 20 years old. Second, age alone may play a role in evaluating any findings of this study; if presumptions about younger 
students being more comfortable with technology or simply more technology-savvy are accurate, it may be that younger students respond differently as a group to online elements of learning. It may also reflect different needs or expectations of this demographic; students of this age and demographic may not need the convenience of online-only coursework, or may feel they benefit more from direct face-to-face interaction with instructors and their fellow students. In comparison, in the online section, gender was more evenly matched with the majority of students self-identifying as white, but with a mean age of 31 and standard deviation of 12.29 ; this confirms that the online group included more non-traditional students.

\section{Experience or Prior Training}

When asked to choose any of the four options pertaining to the student's experience or prior training in the course content (i.e. computer literacy), the highest ranking items was "a post-secondary course on technology (prior to the current course)" with 23 respondents selecting this item. The second highest option ranking was for "at least one high school class that focuses specifically on technology (e.g. keyboarding, computer technology)". This seems to be related to the ages of the survey participants. While the younger students have been exposed to technology since an early educational setting, perhaps the older students had not experienced an introduction to technology while in the K-12 setting.

The third ranking option "at least one high school class is which the teacher made extensive use of technology (computer use, internet applications)" is somewhat smaller than the previous two options. This again may be in part due to the age of the respondents. In the online section, the average age was 31 with a 12.29 standard 
deviation. As technology has evolved rapidly into more areas of life, the younger students have had more exposure in the educational setting than perhaps an older student who left the K-12 environment several years before the use of technology was so prevalent.

Lastly, the lowest ranked option "an employment-based training on some aspect or application of technology" may also be related to age as discussed previously. The older adult student will most likely be in the workforce and had dealings with technology in that setting.

\section{DELES Scale 1 - Instructor Support}

That the overall group mean for this scale was higher for the online group compared to the hybrid group seems counterintuitive, given that the instructor was with the hybrid class for $50 \%$ of class time. The online group had to communicate through technology instead of one-on-one interaction, and indeed the online group found that the instructor was more difficult to contact than the hybrid group. In contrast, there was at least some indication that the hybrid format, allowing direct instructor interaction, was perceived as a benefit. One student in the blended learning environment stated, "It helped me to learn material from the professor in class, and then to come home and practice the material on my own." This would seem to be a distinct advantage the hybrid students have over the online group.

From these responses, it would seem that the instructor plays an important role in providing the students with guidance and assistance whether the student is present with the instructor or online only. In other words, instructor availability and support would seem to be key to the students' positive perception of the course. Respondents in both 
groups appeared to value confirmation and communication from the instructor, whether the message was positive or negative, regarding their progress and/or success in completing the course material and understanding the concepts. It may be that the difference in means, favoring the online group, were related to the experiences of the specific students in these hybrid classes. For example, the hybrid group felt that the instructor was not as responsive to their questions, though again this seems counterintuitive based on the time spent in classroom with the instructor as compared to the online group. A simple interpretation here may be that instructors need to provide feedback to the students whether it be negative or positive. As one student reported from the hybrid group, "The professor was always available to answer any questions a student had." While not all comments were positive in this regard, feedback provided promptly did seem to influence students' perceptions of the course.

\section{DELES Scale 2 - Student Interaction and Collaboration}

Both course delivery methods were reported to have low interaction and collaboration rates, which would be expected. While no student interaction or collaboration was explicitly required in either modality, a question that remains is whether this is something students express a need or desire for. Obviously, if this is so, perhaps instructors of both online and blended courses should work toward facilitating

and encouraging more interaction among students, both through meetings that may occur in person (hybrid) or through the online discussion board or other tools available in the primary learning management system (Blackboard) used in both formats.

In this survey, the hybrid group rated interaction and collaboration higher than the online students, though again this seems to reflect their experience in the course rather 
than a desire or preference for this type of interaction. And while the absence of data should interpreted cautiously, no comments were made by the students in response to the open-ended question addressed concepts covered by this scale.

\section{DELES Scale 3 - Personal Relevance}

The online students rated learning things about the world as the highest item on this scale. A possible explanation for this may relate to demographic, experience, or prior learning variables. As an individual gains more experience in the workplace, having constructs in the course that pertain directly to their work setting would be useful for transference of the material. Especially when instructors know their students are older, and/or are more likely in the workforce, assignments and exams geared toward "real world" examples to reach a more mature audience might be associated with students' perceptions of distance learning. As a student in the online section said, "I use everything I learn at work every single day, making me a more valuable employee and a worthy competitor for advancement!”

In contrast, the hybrid group rated pursuit of topics of interest as the highest item on this scale. A possible explanation here may relate to the demographics of this group, and specifically to their mean age being 20 . While the younger student may not be so immersed in his/her chosen field at such a young age, areas of interest in personal settings may be more pertinent to their learning. As such, assignments and exams that use current, popular cultural themes or references may increase students' positive perceptions of distance learning.

Overall, the mean for the online group was much higher than the hybrid group for this scale. In the past, online students were older students who had personal situations or 
employment that necessitated taking classes via distance education. The older population had more life experiences to relate to the world outside the classroom. More recently, research has shown, "Younger students are one of the fastest-growing segments of the online student population, with age decreasing over time at both the undergraduate and graduate levels. The mean age of undergraduate online students decreased from 34 years old in 2012 to 29 in 2016." (Clinefelter \& Aslanian, 2016, p. 19). Future research could examine whether this past demographic affected this rating given that the age of students enrolled in online learning has decreased in recent years.

\section{DELES Scale 4 - Authentic Learning}

Scales 3 and 4 appear similar in constructs and results. The statements for each scale directly question whether the student can relate the materials to the "real world" or use "real world" examples in the material. The online group mean for Authentic Learning was higher than the hybrid group mean. Of potential importance here is the demographic difference between the groups; the average age of students in the online group was 31 years, compared to 20 years in the hybrid group. It would seem that older students have experienced more "real world" situations. One student in the online group stated, "I enjoyed working with office and excel, and learned several new techniques I can apply to my daily activities and job duties." This further validates that authentic learning is important to the online learner.

To address issues of authentic learning, it seems that instructors in both online and hybrid settings face the same challenges as traditional instructors. Again, all instructors should probably incorporate more real world assignments, or relate the material to personally applicable topics, but this undoubtedly requires that instructors know their 
students, and adapt material accordingly. As another online student stated, "I understand the need for this course for most people, but it was a bit redundant for me personally. . . For someone not as fortunate as me I can see how this would positively impact their life especially when looking for jobs.”

\section{DELES Scale 5 - Active Learning}

The online group mean for this scale, as well as the spread of scores, seemed to indicate a higher rating of active learning by the online students. Here it may be important to consider the specific items in this scale (importantly, only three items): "I explore my own strategies for learning; I seek my own answers; I solve my own problems." While it might be reasonable to interpret fully online learning as relatively less active that hybrid or face-to-face instruction, it may simply be the case that the way these items are worded presents a different conception of 'active learning.' That is, for the purposes of the DELES, these items seem to clearly point to a need for students to be independent and self-motivated in their learning. Thus, those taking the course online may be essentially forced into an active learning mode. Still, both groups rated explore my own strategies for learning as the lowest of the active learning constructs. It may be the case that all learners would prefer the instructor utilize strategies to aid the student instead of him/her seeking out learning skills and strategies. Instructors could use this information to assess and address learning preferences as well as study skill methodology in the course material and projected outcomes and competencies.

\section{DELES Scale 6 - Student Autonomy}

Both groups expressed that they play an important role in my learning, and indeed scores for this scale indicated almost complete overlap between the two groups. 
This may simply indicate that most students realize that it is their responsibility to be an active learner to affect a positive outcome in coursework. However, based on comments, some of the online students felt the low success rate in the course is directly related to the instructor and learning management software used. "The website (software) used to learn/test the Microsoft Suite was buggy." was reported by one student while another shifted the focus to the instructor stating, "Ms. Larkin was as difficult to communicate with as any person I've had to deal with." This may be an important observation, and as I note later, in research on online versus hybrid learning it is exceedingly difficult to tease out effects related to the instructor, versus effects due to content or material, or to course delivery format. Although I tried in this study to minimize this by having the same instructor in all sections of both course formats, it is important not to ascribe comments related to the instructor (i.e., was nice, was not responsive) to the course format.

Both groups also indicated the working during times I find convenient to be the lowest indication in student autonomy. This implies that the students are juggling many aspects of life and study whether the timing is convenient or not. One implication for instructors is the potential need to research what days/times are most convenient for submissions of assignments and testing. Perhaps some students could be better served working at their own pace. Several students commented that they could only attend courses that were offered online only due to the fact that they worked and/or had children. "I was able to keep my job due to the flexibility in the way distance learning is provided, which in turn contributed to me earning a higher position in the corporation as I was completing my classes." This aspect-- perceived as a positive, if not a simple 
requirement-- can not be overlooked as researchers continue to study students' perceptions of the benefits and outcomes of various online learning options.

An example of student autonomy in the online learning environment made by a student, "I get to work in my own time. Online classes also have extended due dates on the assignments and I need that. If it were not for these factors, I would fail or not be able to attend college at all. I work full time, am a single mom and I have no support network." This shows that the student appreciated being work at times that were convenient and make decisions about her learning.

\section{DELES Scale 7 - Distance Education}

The means for this scale were widely different, with the online group rating this construct much higher than the hybrid group. The largest difference appeared to be for question 36: I prefer distance education. Closely behind was the second largest gap, question 40: I look forward to learning by distance. These differences may be explained simply by the fact that the students had two choices for self-selection: online and hybrid. In fact, there seems to be evidence that both groups were satisfied with their choices of format. The online group indicated that the online learning modality is worth their time. The hybrid group indicated satisfaction with the course modality. This may simply be a validation of what has been suspected: students take distance learning courses as they need to due to life circumstances. They appreciate the opportunity to choose an alternate delivery method to the traditional classroom.

\section{Open-Ended Question}

Students were asked to comment regarding the following question: What aspects of the way this course was delivered impacted your success, either positively or 
negatively? Out of the nine students participating in the DELES survey, 7 commented. In the online group, there were 26 comments from the 46 students. I categorized the comments as they related to the Scales.

In reference to Scale 1: Instructor Support, Instructors in online courses (or hybrid, or both) should do more to encourage students as well as provide more feedback whether positive or negative. One would assume the hybrid class would find it favorable to have instructor communication and access. The nature of online learning providing barriers to personal access and interaction between the student and instructor would lend to seeing the instructor in a less favorable light. Instructors would need to realize that this may be an outcome of the delivery mode more so than a reflection of the instructor's actual caring and concern as well as time devoted to the course and students.

As for the students reporting difficulty with the learning management system, MindTap, in the online modality, technology issues in a distance learning setting can often appear. While a student may feel that he/she is adept at computer usage, he/she may not really possess the digital learning skills necessary to perform well in an online computer literacy course. Instructors need to arm the student with technology resources to overcome any technology issues.

While having students appreciate the pedagogy behind course design may be pleasant to hear, instructors may nonetheless be more knowledgeable of good effective course design that helps students to be successful no matter the delivery modality. An ever evolving and learning instructor will continue to revise and plan the subsequent semesters' materials to reach the students in achieving the course competencies and improving student success rates. 
As mentioned in the discussion of Scales 3 and 4, personal relevance and authentic learning are important to students regardless of course format. The larger issue may be simply that all learning must be authentic and relevant, and moves toward online learning must not sacrifice that. This is evident more so in the online group. This may be due to the mean age (31.45), being higher than for the hybrid group. Instructors could use this information to make the course work more relatable and authentic for the learner by providing more work based assignment or exams.

\section{Future Research}

As this was a preliminary, descriptive pilot study, there are several obvious needed areas for further research. I describe below the need to conduct future research that (a) includes broader and more diverse samples, (b) focuses on increased response rates, and (c) includes measures of broader outcomes. This study focused almost exclusively on students' perceptions, and future studies should look at impacts of different learning environments on actual students' performance and outcomes.

Broader and more diverse samples. This survey was conducted from one community and technical college in a large metropolitan area. The participants were enrolled in the computer literacy courses of only one instructor. While this lead to consistency of the materials presented and methodology of the instructor, a wider variety of instructors may yield more significant results.

The hybrid group was comprised of 20 year old students. The students selfselected their enrollment in the blended environment. In contrast, the online group had a mean age of 31. These vast differences in ages may be further researched to address the specific needs of each age group. Future studies conducted with groups that include 
participants of many ages rather than age specific as the hybrid group in this descriptive study may illustrate the ways the methodology affects students' perceptions based on their age.

The diversity of ethnicity and gender was also minimal in the small sample size. With a larger sample and response rate, it would be assumed that a much broader range of ethnicity and gender might result, but in future research this must be carefully targeted. This could potentially lead to more significant differences in perceptions.

Increased response rates. The response rate to the DELES Survey was low. Although the previously discussed research indicated that this was not necessarily an indicator of information that is not valuable in a study, a higher sample size would certainly have enhanced confidence on my findings. There is no question that higher response rates can be assumed to provide more accurate representations of students' perceptions.

Ways to increase response rate may include more student focused timeliness, more reminders, and incentives. One issue with the low sample size is the date at which the survey was sent to the students. This pilot study survey was sent to students from several previous semester courses after a large amount of time had passed from the course completion date for some courses. Perhaps if the survey had been administered at the end of each semester as a requirement to have access to the final exam, the response rate would have been higher. The instructor could have encouraged the students to do so while still enrolled in the class, though this was complicated in the present study because the instructor was the researcher in this case. Finally, some of the students may have no 
longer been enrolled after the semester in which he/she took the class. If so, the student email used to contact him/her would no longer have been valid.

In this preliminary research, the students were emailed twice regarding the survey. In future data collection, perhaps the students could be reminded more and in varying methods (i.e., text, phone calls, alerts). Lastly, the students may have been more willing to participate in the survey had they been given an incentive. If the survey had been distributed in a more timely manner coinciding with the ending of a semester, the instructor could provide bonus points for completion (a nominal amount that would not affect the student outcome in the course) or perhaps enter the participating students in a drawing for a prize.

Another option to consider is using a paper and pencil survey as opposed to an online computer based tool. The survey could have been directly given to the hybrid students in the classroom. It could have been mailed to the strictly online students. This could have yielded higher response rates especially with those students who were luddites in the technology realm to begin with and only took an online class due to the convenience it provided.

Broader measures of outcomes. This study focused exclusively on students' perceptions of their learning experiences. I did not assess (a) performance in class (e.g., class assignments, grades), or (b) longer term outcomes, such as students' application of what they learned to other classes in their program to their job, or to their everyday lives. Future studies could look at these outcomes by comparing individual scores on specific competency based outcomes assessed during the course. Student success rates and pass 
rates from the courses could be analyzed for any significant findings and differences between the hybrid and online groups.

A more qualitative aspect to measurement would be to conduct interviews with former students shortly after completing the coursework to determine if the competencies taught were applicable to everyday tasks or work-related situations. This could be revisited at a later date to produce a more robust study.

\section{Conclusion}

The purpose of this study was to analyze the perceptions of community college students enrolled in an introductory computer literacy course in terms of their experiences in learning computer literacy content through one of two course delivery methods. The instructor and materials presented as well as the course competencies in all sections of the course were identical and consistent through both delivery methods. Provided these constants, the study was designed to assess how students perceived these learning environments, and to the extent possible whether one course delivery method was perceived to be different from the other.

Although findings must interpreted with great caution, due primarily to low response rates, a sample limited to one community college, and a focus on perceptions alone rather than broader outcomes, the study leads to a number of preliminary conclusions. First, it appears that one key outcome from the survey is that instructors need to provide constant and prompt feedback to the students whether it be negative or positive communication. This had much impact on the students' perceptions as indicated in the open-ended question. 
Second, being able to apply the course content to workplace or life situations was valuable to the students in the online section more so than the hybrid section. Again, this is hypothesized to potentially be related to differences in age (and thus experience), but this would be an important area for further research.

Third, while there was some negativity from the students enrolled in the online section, overall the comments in the open-ended questions portrayed the instructor in a positive light. This is especially evident in the hybrid section. I hoped this would be the case since the hybrid students spent $50 \%$ of the instruction time with the instructor. As for the online students, while many of them had positive comments, there may be a number of reasons for a more negative slant to some of their comments. For example, it may be easier to criticize an instructor online when no face-to-face interaction is involved, when the course is not producing the grade you seek or the material is more difficult to learn than anticipated. And comments from the online groups were not all negative; one online student remarked, "Content was taught by the instructor very prompt and thorough which makes this instructor recommended and made a positive impact on me."

Finally, as with any study, more questions are left unanswered. Areas for further research include not only capturing data from more and more diverse students, but data on broader outcomes, including long term outcomes. Technology is a rapidly, ever changing organism. When this study was conducted, the technology was already evolving to a point that the results obtained here may be outdated very soon due to further advances in technology. That said, there is much more that can be done to assess 
students' perceptions of online learning to continually improve and enhance the level of learning in distance education.

Distance education will continue to grow as institutions are faced with uncertain financial futures and can enroll many more students into an online section of a course without being physically bound by classroom size. Students with busy lifestyles and careers will force higher education to provide more individualized delivery methods for coursework. The research into the evolution of online learning must continually be conducted to enhance our understanding of how eLearning impacts students and student outcomes and must keep pace with emerging technology. 


\section{REFERENCES}

Adams, A., Randall, S., \& Traustadóttir, T. (2014). A tale of two sections: An experiment to compare the effectiveness of a hybrid versus a traditional lecture format in introductory microbiology. CBE Life Science Education, 14, 1-8.

Allen, I. \&. Seaman, J. (2005). Growing by degrees: Online education in the United States, 2005. Needham, MA: Sloan Consortium.

Allen, E. I., \& Seaman, J. (2006). Making the grade: Online education in the United States 2006. Needham, MA: Sloan Consortium.

Allen, I. \&. Seaman, J. (2009). Learning on demand: Online education in the United States, 2009. Needham, MA: Sloan Consortium.

Allen, I. \&. Seaman, J. (2010). Class differences: Online education in the United States, 2010. Needham, MA: Sloan Consortium.

Allen, I. \&. Seaman, J. (2015). Grade level: Tracking online education in the United States. Wellesley, MA: Online Learning Consortium.

Anderson, G., \& Walberg, H. (1968). Classroom climate and group learning. Educational Sciences - An International Journal, 2, 175-180.

Anderson, G., \& Walberg, H. (1974). Learning environments. In H. J. Walberg (Ed.), Evaluating Educational Performance (pp. 81-98). Berkeley: McCutchan Publishing.

Black, G. (2002). A comparison of traditional, online, and hybrid methods of course delivery. Journal of Business Administration Online 1(1).

Botsch, C., \& Botsch, R. (2001). Audiences and outcomes in online and traditional American Government classes: A comparative two-year case study. PS: Political Science and Politics, 34, 135-141.

Brick, J. M., \& Williams, D. (2013). Explaining rising nonresponse rates in crosssectional surveys. The ANNALS of the American Academy of Political and Social Science, 645(1), 36-59. https://doi.org/10.1177/0002716212456834

Carlson, E. \& Goss, J. (2016). The state of the urban/rural digital divide. National Telecommunications and Information Administration, United States Department of Commerce. https://www.commerce.gov/news/blog/2016/08/state-urbanruraldigital-divide 
Clauser, B. (2007). The life and labors of Francis Galton: A review of four recent books about the father of behavioral statistics, Journal of Educational And Behavioral Statistics, 32, 440-444.

Clinefelter, D. L. \& Aslanian, C. B. (2016). Online college students 2016: Comprehensive data on demands and preferences. Louisville, KY: The Learning House, Inc.

Collopy, R., \& Arnold, J. M. (2009). To blend or not to blend: Online and blended learning environments in undergraduate teacher education. Issues in Teacher Education, 18, 85-101.

Cook, C., Heath, F., \& Thompson, R. L. (2000). A meta-analysis of response rates in web- or internet-based surveys. Educational and Psychological Measurement, 60, 821-836. https://doi.org/10.1177/00131640021970934

Cosgrove, S. B., \& Olitsky, N. H. (2015). Knowledge retention, student learning, and blended course work: Evidence from principles of economics courses. Southern Economic Journal, 82, 556-579.

Dobbs, R.R., Waid, C.A. \& del Carmen, A. (2009). Students' Perceptions of Online Courses: The Effect of Online Course Experience. Quarterly Review of Distance Education. 10 (1), pp. 9-26.

Dommeyer, C. J., Baum, P., Hanna, R. W., \& Chapman, K. S. (2004). Gathering faculty teaching evaluations by in-class and online surveys: their effects on response rates and evaluations. Assessment \& Evaluation in Higher Education, 29, 611623. doi: $10.1080 / 02602930410001689171$

Driscoll, A., Jicha, K., Hunt, A., Tichavsky, L., \& Thompson, G. (2012). Can online courses deliver in-class results? A comparison of student performance and satisfaction in an online versus a face-to-face introductory sociology course. Teaching Sociology, 40, 312-331.

Fernández-Pascual, M. D., Ferrer-Cascales, R., Reig-Ferrer, A., Albaladejo-Blázquez, N., \& Walker, S. L. (2015). Validation of a Spanish version of the Distance Learning Environments Survey (DELES) in Spain. Learning Environment Research Journal. Online pre-release,1387-1579. Doi: 10.1007/s10984-0159179-0

Ferrer-Cascales, R., Walker, S., Reig-Ferrer, A., Fernández-Pascual, M., \& AlbaladejoBlázquez, N. (2011). Evaluation of hybrid and distance education learning environments in Spain. Australasian Journal of Educational Technology, 27, 1100-1110. doi: https://doi.org/10.14742/ajet.906 
Fosnacht, Kevin, Sarraf, Shimon, Howe, Elijah, \& Peck, Leah. (2017). How important are high response rates for college surveys? The Review of Higher Education, 40, 245-265. Doi: 10.1353/rhe.2017.0003

Fraser, B. J. (1986). Classroom environment. London: Croom Helm.

Ganesh, G., Paswan, A., \& Sun, Q. (2015). Are face-to-face classes more effective than online classes? An empirical examination. Marketing Education Review, 25, 6781.

Jackson, M. \&. Helms, M. (2008). Student perceptions of hybrid courses: Measuring and interpreting quality. Journal of Education for Business, 84(1), 7-12.

Jegede, O., Fraser, B. J., \& Fisher, D. L. (1998, April). The Distance and Open Learning Environment Scale: Its development, validation and use. Paper presented at the 69th Annual Meeting of the National Association for Research in Science Teaching, San Diego, CA, March.

Lim, D. H., Morris, M. L., \& Kupritz, V. W. (2007). Online vs. blended learning: Differences in instructional outcomes and learner satisfaction. Journal of Asynchronous Learning Networks, 11(2), 27-42.

Martin, J., Kreiger, J., \& Apicerno, A. (2015). Effectiveness of a hybrid classroom in the delivery of medical terminology course content. Journal of the Scholarship of Teaching and Learning, 15(5), 72-81.

Massey, Douglas \& Tourangeau, Roger. (2013). Where do we go from here? Nonresponse and social measurement. The ANNALS of the American Academy of Political and Social Science, 645, 222-236. Doi: 10.1177/0002716212464191

Miller, B., Cohen, N. L., \& Beffa-Negrini, P. (2001). Factors for success in online and face-to-face instruction. Academic Exchange Quarterly, 5(4), 4-10.

MindTap (n.d.). Student Assessment Model (SAM). MindTap, Cengage Learning. Boston, MA: https://www.cengage.com/contact.

Moos, R. H. (1974). Systems for the assessment and classification of human environments: An overview. In R. H. Moos \& P. M. Insel (Eds.), Issues in Social Ecology: Human milieus (pp. 5-29). Palo Alto, CA: National Press Books.

National Center for Education Statistics. (2018). Integrated Postsecondary Education Data System (IPEDS). Washington, DC: U.S. Department of Education.

National Student Clearinghouse Research Center. (2018). Term Enrollment Estimates Current Spring 2018. Retrieved from https://nscresearchcenter.org/wpcontent/uploads/CurrentTermEnrollment-Spring2018.pdf. 
Nulty, D. D. (2008). The adequacy of response rates to online and paper surveys: what can be done? Assessment \& Evaluation in Higher Education, 33, 301-314.

Purcell, K., Heaps, A., Buchanan, J. \& Friedrich, L. (2013). How teachers are using technology at home and in their classrooms. Pew Research Center, retrieved from http://pewinternet.org/Reports/2013/Teachers-and-technology.

Tai, X., Smith, A. M., McGeer, A. J., Dubé, E., Holness, D. L., Katz, K., Hall, L. M., McNeil, S. A., Powis, J., \& Coleman, B. L. (2018). Comparison of response rates on invitation mode of a web-based survey on influenza vaccine adverse events among healthcare workers: a pilot study. BMC Medical Research Methodology, 18, 59. https://doi.org/10.1186/s12874-018-0524-8

Tsai, C.-W., Shen, P.-D., \& Tsai, M.-C. (2011). Developing an appropriate design of blended learning with web-enabled self-regulated learning to enhance students' learning and thoughts regarding online learning. Behavior and Information Technology, 261-271.

Valentine, J. C., Aloe, A. M., \& Lau, T. S. (2015). Life after NHST: How to describe your data without "p-ing" everywhere. Basic And Applied Social Psychology, 37:260-273.

Walker, S., \& Fraser, B. (2004, April 12). Development and validation of an instrument for assessing distance education learning environments in higher education: The Distance Education Learning Environments Survey (DELES). Paper presented at the 2004 Annual Meeting of the American Educational Research Association, San Diego, CA. Retrieved September 11, 2005, from http://uweb.txstate.edu/ sw36/DELES/AERA_2004/

Walker, S. L., \& Fraser, B. J. (2005). Development and validation of an instrument for assessing distance education learning environments in higher education: The Distance Education Learning Environments Survey (DELES). Learning Environments Research, 8, 289-308.

Walberg, H. J. (1968). Teacher personality and classroom climate. Psychology in the Schools, 5, 163-169. doi:10.1002/1520-6807(196804)5:2<163::AIDPITS2310050215>3.0.CO;2-T

Walberg, H. J. (Ed). (1979). Educational environments and effects: Evaluation, policy and productivity. Berkeley, CA: McCutchan.

Watt, S., Simpson, C., McKillop, C., \& Nunn, V. (2002). Electronic course surveys: Does automating feedback and reporting give better results?. Assessment \& Evaluation in Higher Education, 27, 325-337. Doi: 10.1080/0260293022000001346 
Zimmerman, B. J., Bonner, Sebastian, \& Kovach, Robert. (1996). Developing selfregulated learners: Beyond achievement to self-efficacy. Washington, DC: American Psychological Association. 
APPENDICES 
Appendix A

Recruitment Materials 
[This is the text for the emails to be used to send survey link to potential participants. Note that the preamble (attached elsewhere) will be embedded as the first page of survey itself within Qualtrics. Included here is the initial email, and a follow up email to be sent 7 days after the initial email is sent]

\section{[Initial email]}

\section{Dear JCTC Student:}

You are receiving this email because you took a class from Professor Pamela Larkin this past year. We invite you to participate in a brief survey about your experiences in that class. We are hoping to learn more about students' perceptions of the format through which this course was delivered - note that we are NOT evaluating the instructor of the course.

The link below will take you to the survey. We anticipate it will take no more than about 10 minutes to complete the survey. As explained on the first page you will see when clicking on this link, your participation is completely voluntary, and your identity will not be known to us or linked with your specific survey responses in the data we collect.

Thank you for considering participating in this survey.

Timothy J. Landrum, PhD, Professor

Pamela Larkin, Doctoral Student

University of Louisville

Survey Links:

Hybrid students:

https://louisvilleeducation.az1.qualtrics.com/ife/form/SV_eDnDi5tgP8Gh4YR

Online students: https://louisvilleeducation.az1.qualtrics.com/ife/form/SV 0MuDi71bq7V9Iax 
Appendix B

Follow Up Email 


\section{[Follow up email]}

\section{Dear JCTC Student}

This email is just a reminder that about a week ago you should have received an invitation to participate in a survey regarding a class you took with Professor Pamela Larkin this past year (the original email appears below). If you have already participated, thank you! We appreciate your responses. If you have not participated but wish to do so, we hope that you will be able to complete the survey within the next 7 days.

Thanks again for considering participating in this survey.

Timothy J. Landrum, PhD, Professor

Pamela Larkin, Doctoral Student

University of Louisville

Survey Links:

Hybrid students:

https://louisvilleeducation.az1.qualtrics.com/ife/form/SV eDnDi5tgP8Gh4YR

Online students:

https://louisvilleeducation.az1.qualtrics.com/ife/form/SV 0MuDi71bq7V9Iax

\section{Original email}

\section{Dear JCTC Student}

You are receiving this email because you took a class from Professor Pamela Larkin this past year. We invite you to participate in a brief survey about your experiences in that class. We are hoping to learn more about students' perceptions of the format through which this course was delivered — note that we are NOT evaluating the instructor of the course.

The link below will take you to the survey. We anticipate it will take no more than about 10 minutes to complete the survey. As explained on the first page you will see when clicking on this link, your participation is completely voluntary, and your identity will not be known to us or linked with your specific survey responses in the data we collect.

Thank you for considering participating in this survey.

Timothy J. Landrum, PhD, Professor

Pamela Larkin, Doctoral Student

University of Louisville 
Appendix C

Survey Preamble 


\section{Preamble}

You are being invited to participate in a research study by answering questions on the attached survey about your perceptions of the learning environment you experienced in class you recently completed with Professor Pamela Larkin. Please note that the survey does NOT ask you to evaluate the instructor of this course; this survey is designed to help us learn about the formats through which these courses are delivered. This study is conducted by Dr. Timothy Landrum and Pamela Larkin of the University of Louisville. There are no known risks for your participation in this research study. The information collected may not benefit you directly. The information learned in this study may be helpful to others. The information you provide will help us understand students' perceptions of the formats through which courses like this are delivered. Your completed survey will be uploaded to the Qualtrics and then transferred and stored on a secure research computer at the University of Louisville. The survey will take approximately 15-20 minutes to complete. Individuals from the Department of Special Education, the Institutional Review Board (IRB), the Human Subjects Protection Program Office (HSPPO), and other regulatory agencies may inspect these records. In all other respects, however, the data will be held in confidence to the extent permitted by law. Should the data be published, your identity will not be disclosed. Taking part in this study is voluntary. By answering survey questions you agree to take part in this research study. You do not have to answer any questions that make you uncomfortable. You may choose not to take part at all. If you decide to be in this study you may stop taking part at any time. If you decide not to be in this study or if you stop taking part at any time, you will not lose any benefits for which you may qualify.

If you have any questions, concerns, or complaints about the research study, please contact:

Tim Landrum at (502) 852-0952, email: t.landrum@louisville.edu or Pamela Larkin at (502) 213-3645, email: pamela.larkin@kctcs.edu

If you have any questions about your rights as a research subject, you may call the Human Subjects Protection Program Office at the University of Louisville at (502) 8525188. You can discuss any questions about your rights as a research subject, in private, with a member of the Institutional Review Board (IRB). You may also call this number if you have other questions about the research, and you cannot reach the research staff, or want to talk to someone else. The IRB is an independent committee made up of people from the University community, staff of the institutions, as well as people from the community not connected with these institutions. The IRB has reviewed this research study.

If you have concerns or complaints about the research or research staff and you do not wish to give your name, you may call 1-877-852-1167. This is a 24 hour hot line answered by people who do not work at the University of Louisville.

Sincerely 
Timothy Landrum, Ph.D.

Pamela Larkin, MAT

\section{CONSENT}

I have read this form and agree to participate in this study.

o Yes

o No

[participants will click YES to continue and complete the survey] 
Appendix D

Demographic Form 


\section{Demographic Form}

Age (years):

Gender: $\mathrm{M}_{\text {__ }} \mathrm{F}$

Ethnicity:

African American

Asian/Pacific Islander

Caucasian

_ Native American/Alaska Native

_ Other:

Experience or prior training with technology (Please check all that apply)

I have participated in or completed:

_ at least one high school class that focused specifically on technology (e.g.,

keyboarding, computer technology)

_ at least one high school class in which the teacher made extensive use of technology

(computer use, internet applications)

a post-secondary course on technology (prior to the current course) an employment-based training on some aspect or application of technology;

describe: 


\section{Appendix E}

Distance Education Learning Environments Survey (DELES) 


\title{
Distance Education Learning Environments Survey (DELES)
}

\author{
(Walker \& Fraser, 2005)
}

For each item, respondent indicates:

$4=$ always, $3=$ often, $2=$ sometimes, $1=$ seldom, or $0=$ never .

\begin{tabular}{|c|c|}
\hline Scale & Items \\
\hline \multirow[t]{9}{*}{ Instructor support } & In this class... \\
\hline & 1. If I have an inquiry, the instructor finds time to respond. \\
\hline & 2. The instructor helps me identify problem areas in my study. \\
\hline & 3. The instructor responds promptly to my questions. \\
\hline & 4. The instructor gives me valuable feedback on my assignments. \\
\hline & 5. The instructor adequately addresses my questions. \\
\hline & 6. The instructor encourages my participation. \\
\hline & 7. It is easy to contact the instructor. \\
\hline & $\begin{array}{l}\text { 8. The instructor provides me with positive and negative feedback } \\
\text { on my work. }\end{array}$ \\
\hline \multirow{8}{*}{$\begin{array}{l}\text { Student interaction } \\
\text { and collaboration }\end{array}$} & \\
\hline & In this class... \\
\hline & 9. I work with others. \\
\hline & 10. I relate my work to others' work. \\
\hline & 11. I share information with other students. \\
\hline & 12. I discuss my ideas with other students. \\
\hline & 13. I collaborate with other students in the class. \\
\hline & 14. Group work is a part of my activities. \\
\hline \multirow[t]{8}{*}{ Personal relevance } & In this class... \\
\hline & 15. I can relate what I learn to my life outside of university. \\
\hline & 16. I am able to pursue topics that interest me. \\
\hline & 17. I can connect my studies to my activities outside of class. \\
\hline & 18. I apply my everyday experiences in class. \\
\hline & 19. I link class work to my life outside of university. \\
\hline & 20. I learn things about the world outside of university. \\
\hline & 21. I apply my out-of-class experience. \\
\hline \multirow[t]{6}{*}{ Authentic learning } & In this class... \\
\hline & 22. I study real cases related to the class. \\
\hline & 23. I use real facts in class activities. \\
\hline & 24. I work on assignments that deal with real-world information. \\
\hline & 25. I work with real examples. \\
\hline & 26. I enter the real world of the topic of study. \\
\hline Active learning & In this class... \\
\hline
\end{tabular}




\begin{tabular}{|l|l|}
\hline & 27. I explore my own strategies for learning. \\
\hline & 28. I seek my own answers. \\
\hline & 29. I solve my own problems. \\
\hline & In this class... \\
\hline Student autonomy & 30. I make decisions about my learning. \\
\hline & 31. I work during times that I find convenient. \\
\hline & 32. I am in control of my learning. \\
\hline & 33. I play an important role in my learning. \\
\hline & 34. I approach learning in my own way. \\
\hline & In this class... \\
\hline & 35. Distance education is stimulating. \\
\hline & 36. I prefer distance education. \\
\hline & 37. Distance education is exciting. \\
\hline & 38. Distance education is worth my time. \\
\hline & 39. I enjoy studying by distance. \\
\hline & $\begin{array}{l}\text { 41. I look forward to learning by distance. } \\
\text { distance. }\end{array}$ \\
\hline & 42. I am satisfied with this class. \\
\hline
\end{tabular}

[researcher-developed items]

\section{Rate your agreement with the following items on a 1-4 scale:} $(1=$ strongly disagree, $2=$ disagree, $3=$ agree, $4=$ strongly agree $)$.

1. My knowledge of Microsoft Office increased as a result of this course.

2. My ability to use Microsoft Office components (e.g., Word, Excel, PowerPoint, and Access) increased as a result of this course.

3. This class has positively impacted my use of Microsoft Office in my work place.

Open-ended:

What aspects of the way this course was delivered impacted your success, either positively or negatively? 


\section{Appendix F}

Open-Ended Question for Participants Who Completed DELES Survey by Modality 


\section{Open-Ended Question for Participants Who Completed DELES Survey by Modality}

\begin{tabular}{|c|c|}
\hline & $\begin{array}{l}\text { What aspects of the way this course was delivered impacted your success, either } \\
\text { positively or negatively? }\end{array}$ \\
\hline & Hybrid Modality $(n=9)$ \\
\hline & $\begin{array}{l}\text { Mrs. Larkin was very communicative, I loved having her. We went more in depth with } \\
\text { Microsoft than Ive ever been. Shes a wonderful teacher! }\end{array}$ \\
\hline & The teacher was terrible about telling students business to other people. \\
\hline & Idk \\
\hline & $\begin{array}{l}\text { The professor was always available to answer any questions a student had. She never } \\
\text { handed out the answer, but she gave you the tools necessary to find the answer on your } \\
\text { own. }\end{array}$ \\
\hline & $\begin{array}{l}\text { It helped me to learn material from the professor in class, and then to come home and } \\
\text { practice the material on my own. }\end{array}$ \\
\hline & $\begin{array}{l}\text { Very positive. She made herself readily available when students needed help or were } \\
\text { having difficulty with homework and worked to find solutions and did her best to help } \\
\text { the students succeed in this course. }\end{array}$ \\
\hline & Online Modality $(n=46)$ \\
\hline & $\begin{array}{l}\text { Negatively, the professor did not reply to me promptly after encountering personal issues } \\
\text { and I soon dropped the course after two weeks. }\end{array}$ \\
\hline & $\begin{array}{l}\text { The website (software) used to learn/test the Microsoft Suite was buggy. I even had to } \\
\text { share a screen share video of my desktop so the professor could see I was being truthful } \\
\text { about my barriers. My professor was pretty lenient and helpful when dealing w my issue }\end{array}$ \\
\hline & The course was clear and precise and made it easy to navigate. \\
\hline & $\begin{array}{l}\text { AS A FULL TIME EMPLOYEE, IT ALLOWED ME TIME TO FINISH ON MY OWN } \\
\text { WHILE WORKING }\end{array}$ \\
\hline & Tasks were divided evenly over the semester making time planning a positive experience. \\
\hline & $\begin{array}{l}\text { I get to work in my own time. Online classes also have extended due dates on the } \\
\text { assignments and I need that. If it were not for these factors, I would fail or not be able to } \\
\text { attend college at all. I work full time, am a single mom and I have no support network. } \\
\text { God, my son and I handle everything in our life together. I am very grateful for JCTC and } \\
\text { their online classes. I use everything I learn at work every single day, making me a more } \\
\text { valuble employee and a worthy competitor for advancement! }\end{array}$ \\
\hline & $\begin{array}{l}\text { Ms. Larkin was as difficult to communicate with as any person Iv,e had to deal with. } \\
\text { There were areas in the course she made ambiguous; when we discussed it she seemed to } \\
\text { not understand the issues she created by design. In reality i could have had someone do } \\
\text { all the work for me but she was stuck on only on meeting the imposed time lines(opening } \\
\text { an closing the test windows) while placing barriers to meeting the by not allowing the } \\
\text { student to work a their pace. This issue started in the beginning of the course and was }\end{array}$ \\
\hline
\end{tabular}


never resolved. Its seemed she took pride in having the control to adjust this one thing (everything else was a Good Will YouTube video) and wasn't going to consider my input. She wanted her superior position to be unchallenged. I have an AS and BS from a distance education format and have never experienced a person with this attitude. Content was taught by the Instructor very prompt and thorough which makes this instructor recommended and made a positive impact on me.

Positive

It helped me get a better perspective on what professional employers want to see in and employee and their resume, cover letters

Was great

The teachers help

Positively

I was able to keep my job due to the flexibility in the way distance learning is provided, which in turn contributed to me earning a higher position in the corporation as I was completing my classes

This course was very well set up, which is key when learning by distance. The Professor was very helpful and was thorough in explaining what was expected. I am very satisfied. Neither

The modules where we had to perform steps in a Microsoft system helped on getting familiar with where to find various things

Positively

i enjoyed working with office and excel, and learned several new techniques i can apply to my daily activities and job duties.

It is a bit unfair that I give my survey for this course as I did withdraw a few weeks in. The program just would not work on my computer. Although Mrs.Larkin was understanding of my difficult position and allowed me to withdraw, I found the assistance that I needed to make it work was inadequate.I asked for help when I could not get it to work( I had already posted to the student board asking if anyone could help but no advice they provided worked.) I was told by her to contact tech support, and was offered no help in resolving the matter other than her asking for a screenshot and telling me what I had not completed in the course and the suggestion to contact support.

I understand the need for this course for most people, but it was a bit redundant for me personally. I never got to work with Access so that was extremely useful for me, but my previous education since 3rd grade had me doing the majority of the material. For someone not as fortunate as me I can see how this would positively impact their life especially when looking for jobs.

It was a great experience. I learned a lot that is going to help me in the long run. The ability to work on this class whenever I had time impacted my success positively, because I could sit down and focus at times when I was able to.

Being walked through steps while within a version of the software itself was effective The program on which the assignments were on, it was very sensitive and bugged out very often.

Positive 
Appendix G

KCTCS Information 


\section{KCTCS Information}

KCTCS has adopted current IC3 objectives to define computer literacy. The course description or descriptions, competencies, and outline of computer literacy courses must include IC3 objectives as outlined at http://unity.kctcs.edu/docushare/dsweb/View/Collection-8666

All AA, AS, AAS, and diploma students entering KCTCS must demonstrate computer literacy by:

1. Scoring a passing score on the IC3 Computer Exam*, or

2. Providing documentation of successful completion of certification exams as approved by KCTCS, or

3. Articulating credit from another institution, or

4. Receiving credit for an approved KCTCS computer literacy course.

Note: Students may receive three credit hours for CIT105 or OST105 by successful completion of the IC3 Computer Exam* and one of the following: the IC3 Database Exam*, a one credit hour database course, or the MOS Access exam.

Students may choose to take the IC3 Computer Exam* to demonstrate computer competency. Students who score a passing score on the exam will have met the requirements of computer literacy and documentation will be placed on the student's transcript.

*Full implementation fall 2007

\section{CIT105 - Introduction to Computers}

Hours: 3

Course ID: 004710 
Provides an introduction to the computer and the convergence of technology as used in today’s global environment. Introduces topics including computer hardware and software, file management, the Internet, e-mail, the social web, green computing, security and computer ethics. Presents basic use of application, programming, systems, and utility software. Basic keyboarding skills are strongly recommended.

Components: Lecture [3 credits (45 contact hours)]

\section{Attributes: Digital Literacy}

\section{OST 105 - Introduction to Information Systems}

\section{Hours: 3}

Course ID: 003769

Introduces and familiarizes students with essential computer concepts and terminology including operating systems software, multitasking concepts, disk and file management and telecommunications. Teaches basic competencies in word processing, electronic spreadsheets, presentations, databases, and online skills including networking, electronic mail, Web browsing, and Internet research. (Key $20 \mathrm{wpm}$ is recommended).

Components: Lecture [3 credits (45 contact hours)]

\section{Attributes: Digital Literacy}

From the KCTCS 2016 - 2017 catalog 


\section{CURRICULUM VITAE}

Pamela Bates Larkin

123 Woodfield Circle

Shelbyville, Kentucky 40065

502-633-9712

sandplarkin@twc.com

\begin{tabular}{|c|c|}
\hline EDUCATION & \\
\hline 2001 - present & $\begin{array}{l}\text { Ph.D. Candidate } \\
\text { University of Louisville }\end{array}$ \\
\hline $2001-2002$ & $\begin{array}{l}\text { Future Professors Program } \\
\text { University of Louisville }\end{array}$ \\
\hline 1999 & $\begin{array}{l}\text { Rank I Teaching Certificate } \\
\text { University of Louisville }\end{array}$ \\
\hline 1992 & $\begin{array}{l}\text { Masters of Arts in Teaching } \\
\text { Secondary Teaching Certificate, Rank II } \\
\text { Middle School Teaching Certificate } \\
\text { Vocational Teaching Certificate } \\
\text { University of Louisville } \\
\text { Scholarship for Two Years }\end{array}$ \\
\hline 1991 & $\begin{array}{l}\text { Secondary Teaching Certificate, Rank IV } \\
\text { University of Louisville }\end{array}$ \\
\hline 1986 & $\begin{array}{l}\text { B.S. in Business Administration } \\
\text { Berea College } \\
\text { Scholarship for Four Years }\end{array}$ \\
\hline EXPERIENCE & \\
\hline 2005 - present & $\begin{array}{l}\text { Professor } \\
\text { Administrative Office Technology } \\
\text { Jefferson Community and Technical College } \\
\text { Shelbyville, Kentucky }\end{array}$ \\
\hline $2015-2017$ & $\begin{array}{l}\text { Computer Trainer } \\
\text { Educational Consortium and Industry } \\
\text { Shelbyville, Kentucky }\end{array}$ \\
\hline $2004-2016$ & Division Chair - Shelby County Campus \\
\hline
\end{tabular}




\begin{tabular}{|c|c|}
\hline $1995-2005$ & $\begin{array}{l}\text { Jefferson Community and Technical College } \\
\text { Shelbyville, Kentucky } \\
\text { Associate Professor } \\
\text { Office Technology } \\
\text { Jefferson Community and Technical College } \\
\text { Shelbyville, Kentucky }\end{array}$ \\
\hline $1995-2005$ & $\begin{array}{l}\text { Presiding Partner } \\
\text { Money Makers Investment Club } \\
\text { Shelbyville, Kentucky }\end{array}$ \\
\hline $1992-2006$ & $\begin{array}{l}\text { Accountant } \\
\text { Noel Bates Concrete Construction } \\
\text { Louisville, Kentucky }\end{array}$ \\
\hline $1992-1995$ & $\begin{array}{l}\text { Director of Systems Programming and Design } \\
\text { Automated Telecom, Inc. } \\
\text { Louisville, Kentucky }\end{array}$ \\
\hline $1992-1995$ & $\begin{array}{l}\text { Adjunct Faculty } \\
\text { Computer Information Technology } \\
\text { Jefferson Community College - Southwest Campus } \\
\text { Louisville, Kentucky }\end{array}$ \\
\hline $1991-1992$ & $\begin{array}{l}\text { Teacher } \\
\text { Academic Competition Coordinator } \\
\text { Quick Recall Co-Sponsor } \\
\text { Fairdale High School } \\
\text { Louisville, Kentucky }\end{array}$ \\
\hline $1987-1992$ & $\begin{array}{l}\text { Consultant/Office Manager } \\
\text { Weinberg, O'Koon and Company, CPAs, } \\
\text { Louisville, Kentucky }\end{array}$ \\
\hline AWARDS & \\
\hline 2013 & $\begin{array}{l}\text { Outstanding Faculty Member Serving Adult Learners Nominee } \\
\text { Kentuckiana Metroversity } \\
\text { Louisville, Kentucky }\end{array}$ \\
\hline $2003-2004$ & $\begin{array}{l}\text { President's Leadership Seminar } \\
\text { KCTCS, Versailles, Kentucky }\end{array}$ \\
\hline $2002-2003$ & $\begin{array}{l}\text { Outstanding Faculty Member Finalist } \\
\text { Jefferson Technical College } \\
\text { Louisville, Kentucky }\end{array}$ \\
\hline
\end{tabular}




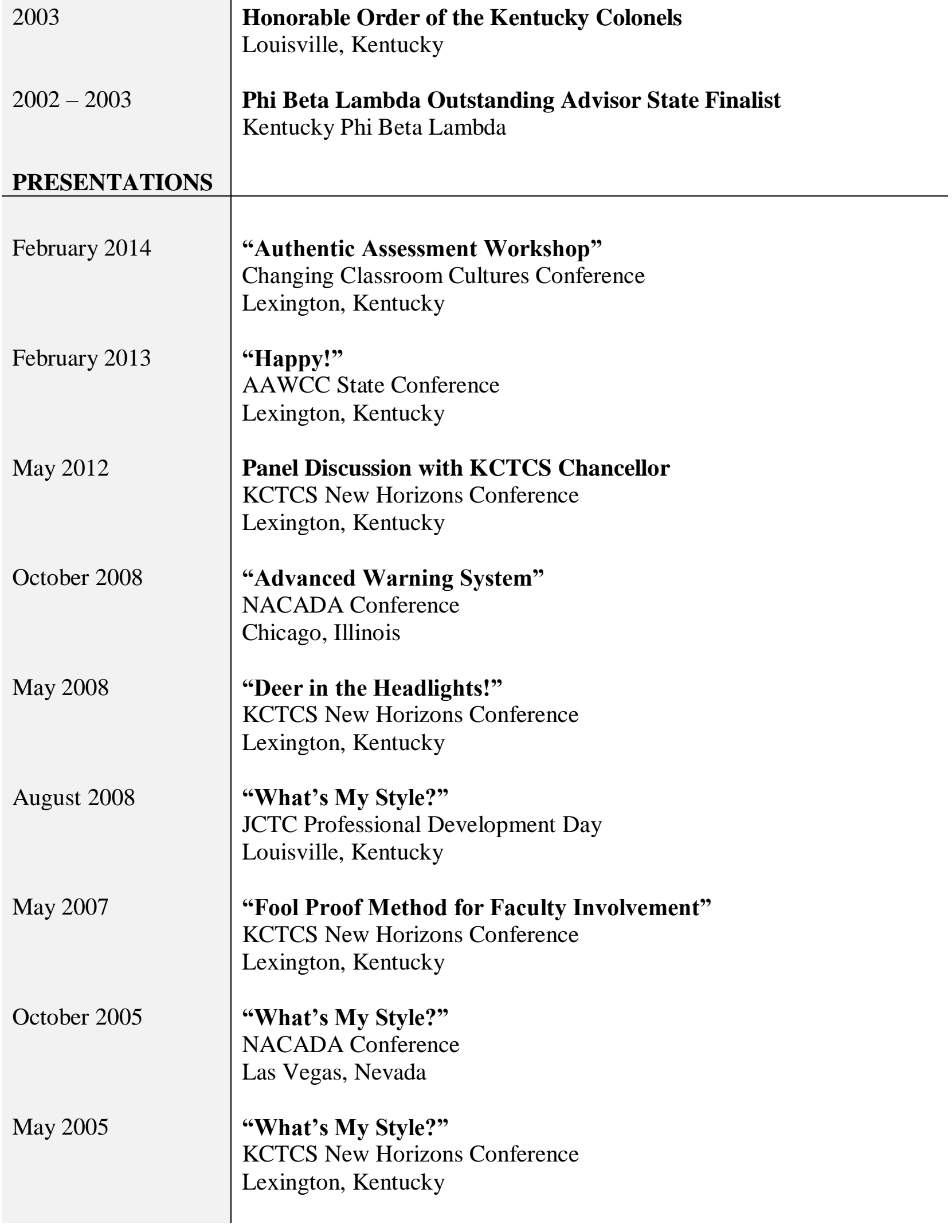


May 2004

November 2004

October 2003

INTERNAL SERVICE

$2014-2016$

$2005-2012$

$2005-2014$

February 2004

$2004-2005$

2003

$2002-2004$
"Building Leaders through the KCTCS President's Leadership Seminar (PLS)"

KCTCS New Horizons Conference

Lexington, Kentucky

"Building the Bridge"

Kentucky Applied Technology Education Association (KATEA) $47^{\text {th }}$

Annual Conference

Luncheon Keynote Speaker with Betsy Langness

Danville, Kentucky

"Building the Bridge"

NACADA National Conference

Dallas, Texas

KCTCS Senate Advisory Committee on Promotion

Versailles, Kentucky

Board of Directors

Jefferson Community and Technical Colleges

Louisville, Kentucky

Faculty and Staff Representative

KCTCS Board of Regents Meeting

Shelby County Campus

Shelbyville, Kentucky

Consolidation Steering Committee

Jefferson Community and Technical Colleges

Louisville, Kentucky

Interim Director

Jefferson Community and Technical Colleges - Shelby County Campus

Shelbyville, Kentucky

Shelby County Campus Advisory Board

Shelby County Campus Advisory Board Strategic Planning

Subcommittee

Jefferson Community and Technical Colleges

Shelby County Campus

Shelbyville, Kentucky 


\begin{tabular}{|c|c|}
\hline $1995-1998$ & $\begin{array}{l}\text { Administrative Office Technology Curriculum Committee } \\
\text { KCTCS } \\
\text { Lexington, Kentucky } \\
\text { Office Technology Curriculum Committee } \\
\text { Cabinet for Workforce Development } \\
\text { Frankfort, Kentucky }\end{array}$ \\
\hline $\begin{array}{l}\text { COMMUNITY } \\
\text { SERVICE }\end{array}$ & \\
\hline 2010 - present & $\begin{array}{l}\text { Code Enforcement Board Member } \\
\text { Chair }(2017 \text { - present) } \\
\text { City of Shelbyville } \\
\text { Shelbyville, Kentucky }\end{array}$ \\
\hline $2001-2002$ & $\begin{array}{l}\text { Governor's Task Force on the Economic Status of Kentucky's } \\
\text { Women } \\
\text { Kentucky Commission on Women } \\
\text { Education and Leadership Committee } \\
\text { Frankfort, Kentucky }\end{array}$ \\
\hline $1994-1999$ & $\begin{array}{l}\text { Shelby County Woman's Club } \\
\text { President - } 1999\end{array}$ \\
\hline
\end{tabular}

